\title{
Roles of Therapeutic Bioactive Compounds in Hepatocellular Carcinoma
}

\author{
Divya Jain, ${ }^{1}$ Yogesh Murti, ${ }^{2}$ Wasi Ullah Khan, ${ }^{3}$ Rajib Hossain, ${ }^{4}$ Mohammad Nabil Hossain, ${ }^{5}$ \\ Krishn Kumar Agrawal, ${ }^{6}$ Rana Azeem Ashraf, ${ }^{7}$ Muhammad Torequl Islam, \\ Pracheta Janmeda $\left(\mathbb{D},{ }^{1}\right.$ Yasaman Taheri $\left(\mathbb{D},{ }^{8}\right.$ Mohammed M. Alshehri $(\mathbb{D})$, \\ Sevgi Durna Daştan, ${ }^{10,11}$ Balakyz Yeskaliyeva, ${ }^{12}$ Aliya Kipchakbayeva, ${ }^{12}$ \\ Javad Sharifi-Rad $\mathbb{D}^{8},{ }^{8}$ and William C. Cho $\mathbb{D}^{13}$ \\ ${ }^{1}$ Department of Bioscience and Biotechnology, Banasthali Vidyapith, Rajasthan, India \\ ${ }^{2}$ Institute of Pharmaceutical Research, GLA University, Mathura, India \\ ${ }^{3}$ Key Laboratory for Sustainable Utilization of Tropical Bioresource, College of Tropical Crops Hainan University, Haikou, China \\ ${ }^{4}$ Department of Pharmacy, Life Science Faculty, Bangabandhu Sheikh Mujibur Rahman Science and Technology University, \\ Dhaka, Bangladesh \\ ${ }^{5}$ College of Chemistry, Chemical Engineering and Biotechnology, Donghua University, Shanghai, China \\ ${ }^{6}$ Faculty of Pharmacy, R.B.S. Engineering Technical Campus, Bichpuri, Agra, India \\ ${ }^{7}$ School of Pharmaceutical Science and Technology (SPST), Tianjin University, China \\ ${ }^{8}$ Phytochemistry Research Center, Shahid Beheshti University of Medical Sciences, Tehran, Iran \\ ${ }^{9}$ Pharmaceutical Care Department, Ministry of National Guard-Health Affairs, Riyadh, Saudi Arabia \\ ${ }^{10}$ Department of Biology, Faculty of Science, Sivas Cumhuriyet University, 58140 Sivas, Turkey \\ ${ }^{11}$ Beekeeping Development Application and Research Center, Sivas Cumhuriyet University, 58140 Sivas, Turkey \\ ${ }^{12}$ Faculty of Chemistry and Chemical Technology, Al-Farabi Kazakh National University, 050040 Almaty, Kazakhstan \\ ${ }^{13}$ Department of Clinical Oncology, Queen Elizabeth Hospital, Kowloon, Hong Kong, SAR, China
}

Correspondence should be addressed to Pracheta Janmeda; pracheta@banasthali.in, Javad Sharifi-Rad; javad.sharifirad@gmail.com, and William C. Cho; chocs@ha.org.hk

Received 4 August 2021; Accepted 6 October 2021; Published 31 October 2021

Academic Editor: ChongDe Sun

Copyright (c) 2021 Divya Jain et al. This is an open access article distributed under the Creative Commons Attribution License, which permits unrestricted use, distribution, and reproduction in any medium, provided the original work is properly cited.

\footnotetext{
Hepatocellular carcinoma (HCC) is due to poor prognosis and lack of availability of effective treatment. Novel therapeutic strategies will be the fine tuning of intracellular ROS signaling to effectively deprive cells of ROS-induced tumor-promoting events. This review discusses the generation of ROS, the major signaling their modulation in therapeutics. We explore some of the major pathways involved in HCC, which include the VEGF, MAPK/ERK, mTOR, FGF, and Ser/Thr kinase pathways. In this review, we study cornerstone on natural bioactive compounds with their effect on hepatocarcinomas. Furthermore, we focus on oxidative stress and FDA-approved signaling pathway inhibitors, along with chemotherapy and radiotherapy enhancers which with early evidence of success. While more in vivo testing is required to confirm the findings presented here, our findings will aid future nonclinical, preclinical, and clinical studies with these compounds, as well as inspire medicinal chemistry scientists to conduct appropriate research on this promising natural compound and their derivatives.
} 


\section{Introduction}

Globally, cancer is the major cause of mortality and morbidity, which can affect almost every organ in the human body [1]. According to the WHO, 1 out of 6 persons die due to cancer. In 2040, it will rise up to 29.4 million cancer cases globally per year [2]. Hepatocellular carcinoma (HCC) is one of the most lethal cancers; in men, it is the fifth, and in women, it is the eighth foremost cause of cancer death worldwide $[3,4]$. There are several ways to inhibit liver cancer such as antioxidant [5], antiproliferative [6], antiinvasive [7], apoptotic [8], antimutagenic [9], anticarcinogenic [10], antitumor [11], and cytotoxic activity [12].

Nature is the big source of natural medicine and compounds derived from plants, animals, marines, and microbes [13-18]. Among them, plants provide many novel anticancer compounds [19] such as alkaloids [20, 21], flavonoids [22, 23], glycosides [24], saponins, tannins [25], and terpenoids [26] which are found from a plant having antioxidant and anticancer properties in a various cancer cell line, especially in a liver cancer cell line. HCC development is a multistep process that may include the alteration in host gene expression, DNA methylation, loss of heterozygosity, and point mutation, but still, we are lacking to determine the rate limiting step for initiation and progression of HCC [27].

As of late, improved information on oncogenic forms and the signaling pathways that manage tumor cell multiplication, differentiation, angiogenesis, invasion, and metastasis has prompted the recognizable proof of a few potential restorative focuses on that have driven the advancement of molecularly focused on treatments [28]. These medications which act straightforwardly on segments of the signaling pathways can control tumorigenesis and have demonstrated clinical advantage in patients with different tumor types. Here, we reviewed significant molecular signaling pathways embroiled in the pathogenesis of HCC and phytochemicals that are involved in the treatments as of now being developed and endorsed for HCC [29].

\section{Signaling Pathways Involved in HCC}

HCC carcinogenesis is a complex multistep process that involves a variety of signaling cascades at the molecular level. The major signaling pathways include vascular endothelial growth factor (VEGF) pathway, mitogen-activated protein kinase (MAPK/ERK) pathway, Wnt $/ \beta$-catenin pathway, phosphatidylinositol-3 kinase (PI3K)/AKT/mammalian target of rapamycin (mTOR) signaling pathway, fibroblast growth factor (FGF) pathway, enzymes reactions generating ROS in liver cancers, enzymatic cycle of P450, mitochondrial dysfunction and signaling, and serine/threonine kinase (AKT) pathway.

2.1. VEGF Signaling Pathway. VEGF is a critical growth factor for angiogenesis during hypervascular HCC cancer development [30]. Deep located tumor cells are required to locate $100-200 \mu \mathrm{m}$ to acquire oxygen and nutrients for survival and proliferation. Tumor size greater than $2 \mathrm{~mm}^{3}$ required angiogenesis [31]. The major members of the fam- ily are VEGF-A, VEGF-B, VEGF-C, VEGF-D, and PIGF, and their potential forms include VEGF-A121 and VEGFA165. VEGF has three main subtypes: VEGFR-1, VEGFR2, and VEGFR-3. They all are embedded in the cell membrane; the extracellular region has a single TM seven immunoglobulins like domains and an intracellular region having a split tyrosine kinase domain [32]. They get phosphorylated after the ligand binding that activates PLC- $\gamma$, which leads to activate the PKC leading to the MAPK signaling pathway and activates endothelial NO that promotes cell proliferation and vascular permeability (Figure 1). It also activates the Rho GTPase [33, 34].

Out of all, VEGFR-2 seems to have a significant job in interceding practically the entirety of the known cell reactions to VEGFs [35]. The initiation of VEGFR-2 prompts endothelial cells to bring about their multiplication, relocation, expanded endurance, and advances vascular penetrability, whereas VEGFR-3 is significant for the lymphangiogenesis [36]. The articulation of VEGF mRNA in liver tumors was found in a larger part of HCC patients. The rule course of HCC dispersal and metastasis is through the entry vein in the liver, and VEGF mRNA level related well with portal vein tumor thrombus (PVTT) development of HCC. Immunohistochemical recognized high VEGF articulation is very much separated from HCC just as regions encompassing the HCC tissues [37]. The most immediate proof supporting the job of the VEGF pathway in HCC originated from late advancement in treatment hindering this pathway.

Bevacizumab (anti-VEGF monoclonal antibodies) are being tested for HCC [38], whereas sorafenib is capable of targeting vascular endothelial growth factor receptor 2 (VEGFR-2) and other proteins to inhibit the tumor angiogenesis [39]. In two significant clinical trials, it has been reported that in the late stage, sorafenib was effective in improving the outcomes of HCC patients.

2.2. Mitogen-Activated Protein Kinase Signaling Pathway. The mammalian mitogen-activated protein kinase (MAPK) family has three members, extracellular signal-regulated kinase (ERK), c-Jun $\mathrm{NH}_{2}$-terminal a kinase (JNK), and p38 that are involved in a variety of cellular activities [40]. Among them, the ERK pathway is involved in promoting cell proliferation, migration, survival, and tumor progression. In the ERK pathway ligand bind with receptor tyrosine kinase (RTKs), this triggers the tyrosine kinase domain activation [41]. That acts as docking sites for GRB2 and SOS proteins. This leads to an activation cascade of small GTPase RAS, Ser/Thr kinase RAF, and MEK [42].

ERK activation can alter the various activities of transcription factors and gene expression level which leads to alteration in cell cycle progression [43]. The phosphorylated ERK (ERK-P) can activate c-myc that regulates cell growth and cell proliferation (Figure 2) [44, 45]. Moreover, it also promotes the survival of cancer cells by regulating the BIM and MCL1 apoptotic pathways [46, 47]. The role of the ERK pathway in HCC is confirmed by AZD6244 (MEK inhibitors) that block cell proliferation and promote programmed cell death in liver carcinoma [48, 49]. 


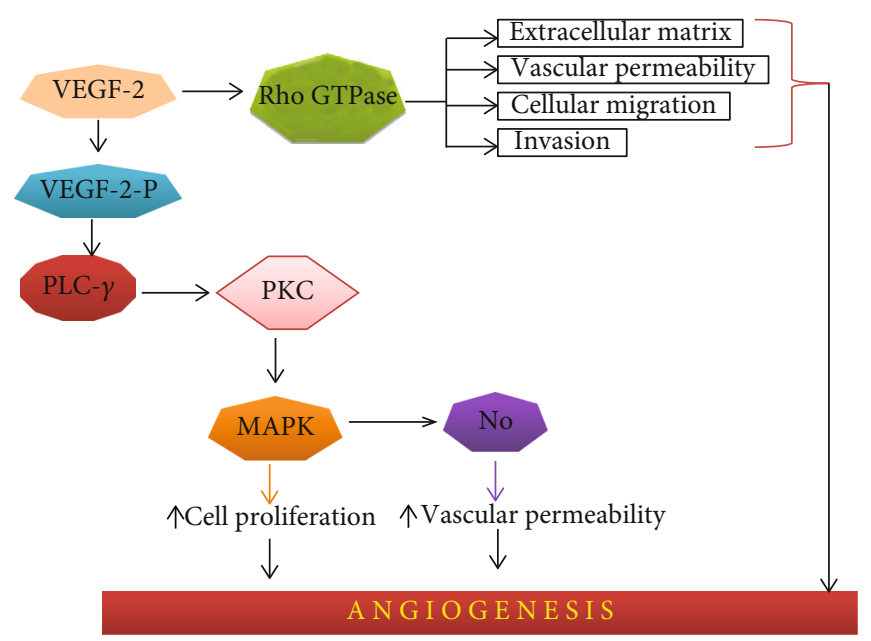

FIGURE 1: VEGF signalling mechanism. VEGF: vascular endothelial growth factor; PLC- $\gamma$ : phospholipase C gamma; PKC: protein kinase C; MAPK: mitogen-activated protein kinase; NO: nitric oxide.

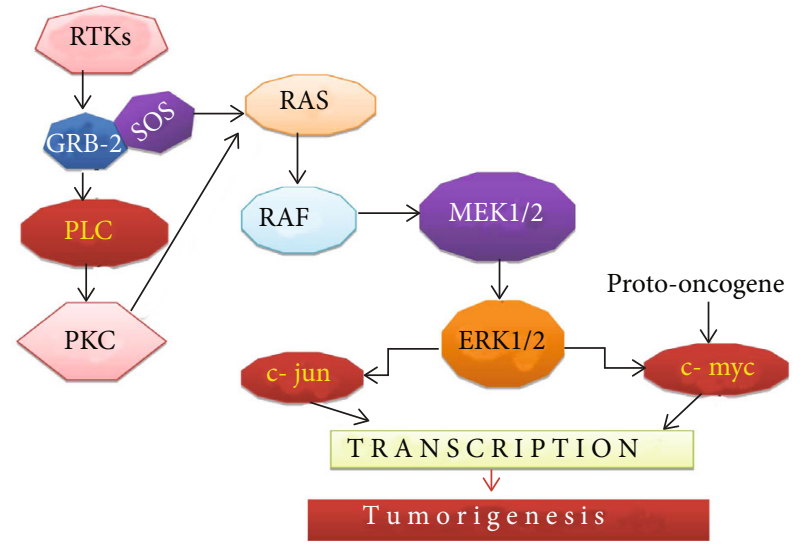

FIGURE 2: Mitogen-activated protein kinase signaling mechanism. RTK: receptor tyrosine kinase; GRB-2: growth factor receptor bound protein-2; SOS: Son of Sevenless; RAF: rapidly accelerated fibrosarcoma; PLC: phospholipase C; PKC: protein kinase C.

Another MAPK signaling pathway includes JNK (JNK-1 and JNK-2) activated by MKK-4 and MKK-7, and downstream substrates include c-Jun [50]. There is strong evidence that JNK-1 increased histone H3 lysine 4 and 9 trimethylations, tumor size that results in the upregulation of cell growth promoting genes [51]. Unlike ERK/JNK pathways, p38 are induced by MKK-3, 4, and 6 and have a suppressive role in HCC [52]. The mechanism behind the p38 activity is the suppression of JNK and the negative regulation of cell proliferation [53].

2.3. Wnt/ $\beta$-Catenin Signalling Pathway. Wnt ligands are cell surface ligands that play a significant role in normal liver function. They form complexes with Frizzled receptors and LRP-5/LRP-6 coreceptors. $\beta$-Catenin forms a complex with various tumor suppressor proteins like APC, axin, and Ser/Thr kinase GSK3 $\beta$ in which APC and axin proteins make structural changes in GSK3 $\beta$ to phosphorylate $\beta$ catenin [54]. This leads to $\beta$-catenin destruction in the cytosol. Upon Wnt binding with a ligand, axin is enlisted to the film to LPR-5, and the $\beta$-catenin demolition complex is then inactivated [55]. This permits the unphosphorylated $\beta$-catenin to aggregate and to move into the nucleus (Figure 3 ). This $\beta$-catenin then structures a complex with a TCF-LEF group of DNA restricting record variables to initiate the TCF-LEF target gene [56]. A significant number of the objective gene is engaged with cell multiplication, i.e., cyclin D1.

Phosphorylated $\beta$-catenin binds with E-cadherin and performs cell to cell adhesion that is a significant process in the development of tumor metastasis. The researcher found strong evidence of $\mathrm{Wnt} / \beta$-catenin's role in liver carcinoma. In most of the HCC cases, the level of $\beta$-catenin is overexpressed that leads to accumulation and results in cell proliferation and inhibiting differentiation. There are likewise considered partner $\beta$-catenin transformations or initiation with compounded HCC result, i.e., bigger tumor size, expanded vascular intrusion, and point mutation or deletion [57].

Such predominant addition of work transformations normally happens at the N-terminal phosphorylation destinations on $\beta$-catenin, including the locales phosphorylated by GSK $3 \beta$ that control $\beta$-catenin debasement. Changes at these positions disturb acknowledgment by GSK3 $\beta$ bringing about increasingly stable $\beta$-catenin protein. In this manner, different reasons for $\beta$-catenin aggregation may exist [58].

It has been demonstrated that the pharmacologic restraint of $\beta$-catenin diminishes the endurance of hepatoma cells. Inactivation of $\beta$-catenin silencer APC prompted the unconstrained improvement of HCC in a mice model, recommending the immediate commitment from actuated Wnt motioning to hepatocarcinogenesis. In any case, parts of the Wnt pathway may speak to potential restorative intercession that focuses on rewarding HCC [59].

2.4. Phosphatidylinositol-3 Kinase (PI3K) Signaling Pathway. A phosphatidylinositol-3 kinase (PI3K)/AKT/mammalian target of rapamycin (mTOR) signaling pathway has a class to the large group of related kinases that have two subunits, i.e., catalytic and regulatory. It is an intracellular signal 


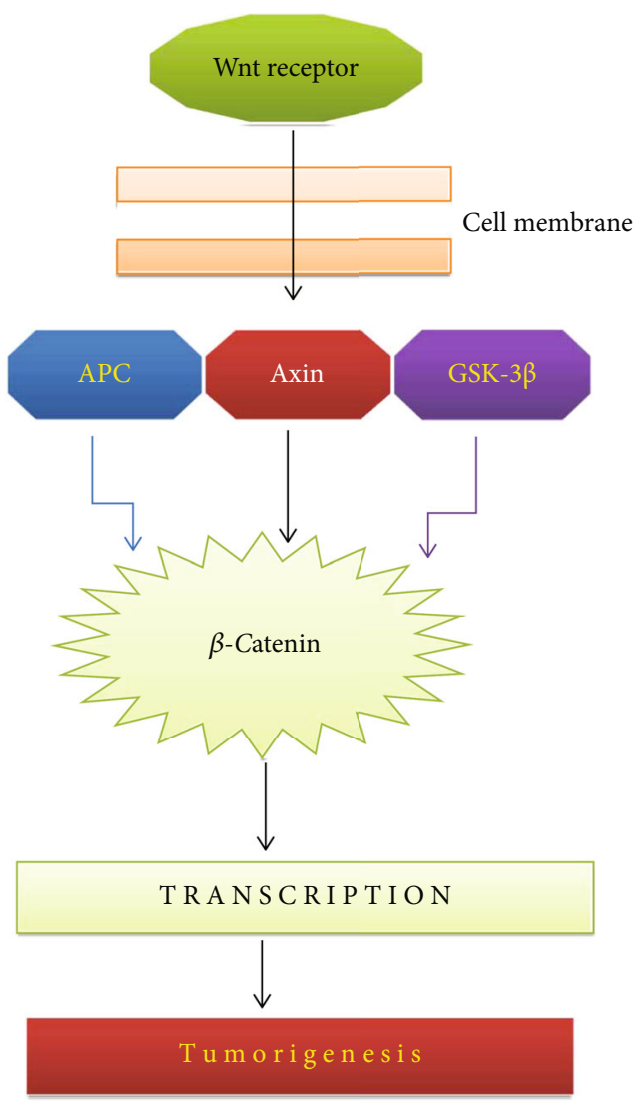

FIGURE 3: Wnt $/ \beta$-catenin signaling pathway. APC: adenomatous polyposis coli; GSK3 $\beta$ : glycogen synthase kinase 3 beta.

transducer enzyme that can phosphorylate the -OH group of phosphatidyl-inositol. The p85 is a regulatory subunit of PI3K that can interrelate with phosphor-tyrosines on activated RTKs that recruit the ligands to the plasma membrane and initiates the enzymatic activities. The lipid second messenger phosphatidyl-inositol-triphosphate (PIT) is activated by $\mathrm{PI} 3 \mathrm{~K}$ in response to activating the PI3K. The downstream ligand of PI3K is AKT kinase having domain on $\mathrm{C}$ terminus that is pleckstrin homology (PH), which binds with PIT and phosphorinositide-dependent kinase 1 (PKDK1) [60].

PDK1 activates the AKT kinase activity that phosphorylates various proteins and manages cellular activities. The downstream effector of AKT is mTOR that belongs to the PI3K family that contains FAT-FATC domains, FRB, and catalytic kinase domains [61]. The AKT phosphorylates the TSC1/TSC2 that activates the Rheb, a small G-protein that finally activates the mTOR for its cellular activity protein translation. Excessive protein translation generally results in abnormal cell growth and tumorigenesis. The negative regulator of this signaling pathway is PTEN that dephosphorylates the PIT [62].

In HCC pathogenesis, reduced PTEN expression has been linked with high recurrence rate, tumor stage, and low survival rate. In the treatment policy, the PI $3 \mathrm{~K} / \mathrm{AKT} / \mathrm{m}$ TOR signaling pathway is upregulated, and inhibitors could play an important role. In addition, everolimus [Afinitor, RAD-001 (40-O-(2-hydroxyethyl)- rapamycin)] is a rapa- mycin analog (rapalog) mTOR inhibitor administered per oral and has been approved by FDA that showed a significant reduction in tumor growth rate by downregulating gene expression which related to ribosomal protein S6 kinase beta-1 (S6K1) and eIF4E-binding protein (4EBP) suppression and inhibits signaling downstream [63].

2.5. Fibroblast Growth Factor Pathway. Fibroblast growth factor (FGF) ligand is a family of 20 different ligands that consist of an extracellular transmembrane domain and intracellular tyrosine kinase domain that is associated with tumorigenesis [64]. Many studies suggested the significant role of FGF in the progression of chronic hepatitis. The tyrosine kinase domains after dimerization can activate the different intracellular signaling pathways [65]. FGF-substrate2 (FRS-2) is an important adaptor of the FGF receptor that can recruit various proteins like SOS and GRB2 after the phosphorylation to activate RAS-GTPase which promotes the different downstream signaling like Wnt, MAPK, and PI3K/AKT pathways as shown in Figure 4 [66]. The downstream signaling of FGF leads to carcinogenesis via angiogenesis. The overexpression of FGFR1 significantly accelerates the growth of HCC in the mouse model [67]. FGF8, 17, and 18 increase the HCC cell survival, and suggesting a role in the progression of HCC, likewise, FGF15 also promotes hepatocellular proliferation in mice that also contribute towards the HCC development. In addition to this, epithelial-to-mesenchymal transition is promoted by FGFR19 that functions via the GSK3 $\beta$ signaling pathway through FGFR4 stimulation [68].

2.6. Enzyme (P450) Reactions Generating ROS in Liver Cancers. Human cytochrome P450s are one of the major sources of ROS. It plays a very important role in maintaining cellular redox species balance which is mandatory for cell signaling and normal cellular functions like an immune response [69]. Normal redox balance is very important for normal organ functioning so that any malfunction cannot lead to various ailments like oxidative stress, aging, and carcinogenesis. Likewise, ROS and RNS can also disrupt biological functions, which lead to cellular damage and oxidative stress [70]. In most cases, variations in structure patterns of lipids, nucleic acids, and proteins are the main targets of ROS. Oxygen radicals by some nonenzymatic oxidation of arachidonic acid form $\mathrm{F}_{2}$-isoprostanes through lipid peroxidation [71]. These $\mathrm{F}_{2}$-isoprostanes not only show their biological effects but are also used as alternate markers to measure ROS levels and oxidative stress [72]. Human CYP2E1 has known to produce ROS through the process of lipid peroxidation, and their products interact with DNA and cause DNA adducts [73], whereas protein modifications through ROS are also possible particularly amino acid cysteine modification can cause downstream signaling in toxic pathways leading to carcinogenesis especially HCC.

ROS are generated in the mitochondria, peroxisomes, cytochrome p450, and other components of the cell [74, 75]. Initially, an electron is provided to $\mathrm{O}_{2}{ }^{-}$that further dismutases to $\mathrm{H}_{2} \mathrm{O}_{2}$. Here, superoxide dismutase converts $\mathrm{O}_{2}$ to $\mathrm{H}_{2} \mathrm{O}_{2}$ which is a stable molecule and can cross membranes. 


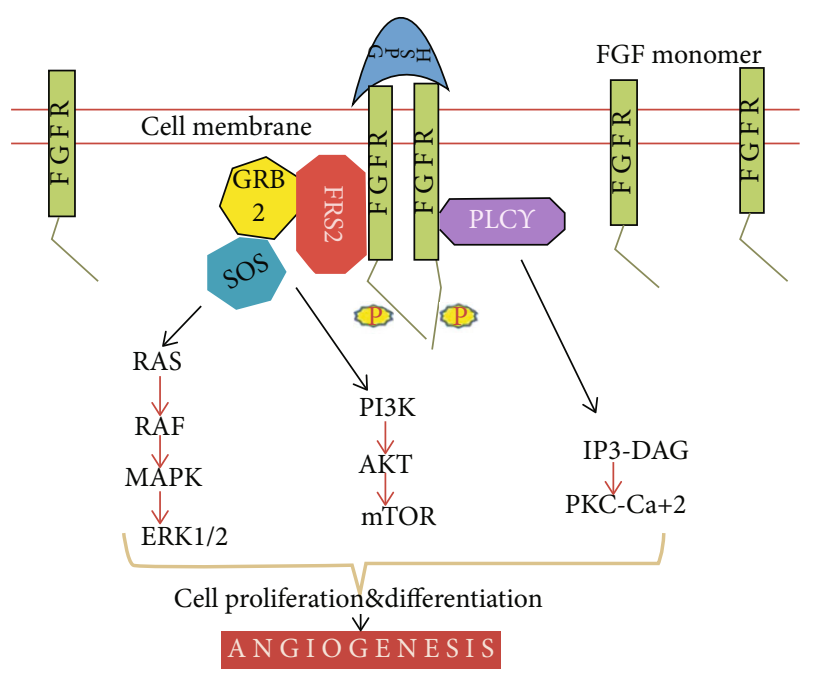

FIGURE 4: Fibroblast growth factor signaling pathway. GBR: growth factor receptor-bound; SOS: Son of Sevenless; PLC $\gamma$ : phospholipase C gamma; MAPK: mitogen-activated protein kinase; ERK1/2: extracellular signal-regulated kinase; PI3K: phospho-inositide-3kinase; AKT: protein kinase B; mTOR: mammalian target of rapamycin; $\mathrm{PKC}-\mathrm{Ca}^{2+}$ : protein kinase $\mathrm{C}-\mathrm{Ca}^{2+}$.

In the cytochrome chain, free radicals are formed when the electrons, donated by FADH and $\mathrm{NADH}$, react with oxygen and other electron acceptors [76] as shown in Figure 5.

2.7. Enzymatic Cycle of P450. Human cytochrome P450s (CYP) are a superfamily of monooxygenases that are primarily known for the oxidation of the vast majority of xenobiotics in phase I metabolism helping in increasing substrate polarity and helping in excretion [77]. CYP generates ROS and how they contribute to an increase in oxidative stress. In the very first step, the substrate $(\mathrm{R}-\mathrm{H})$ binds to the active site of the CYP enzyme via ferric iron $\left(\mathrm{Fe}^{3+}\right)$ of the heme thiolate group (Figure 6). In the second step, the heme thiolate group receives one electron from the NADPH regenerating system and CPR cytochrome peroxidase reductase (redox partner of CYP enzyme) and gets reduced to $\mathrm{Fe}^{+2}$. This is the time when molecular oxygen binds to $\mathrm{O}_{2}$ and $\mathrm{CPR}$, then donates the second electron and reduces the $\mathrm{Fe}^{2}$ ${ }^{+-} \mathrm{O}_{2}$ complex which activates oxygen in the complex $\left(\mathrm{Fe}^{2}\right.$ $\left.{ }^{+-} \mathrm{O}_{2}{ }^{-}\right)$. In the next step $\left(\mathrm{H}^{+}\right)$, ions get into the active site by some special ion channels and cleave the $\mathrm{O}-\mathrm{O}$ bond and release water. The complex $\left(\mathrm{FeO}_{2}{ }^{+3}\right)$ then removes a proton in the step from the substrate and leaves an intermediate $\mathrm{RFe}^{3+} \cdot \mathrm{OH}^{-}$. In the last step, the $-\mathrm{OH}$ hydroxyl group is transferred to the substrate radical and the oxidized substrate is released at the end (Figure 7). The latest research is underway to specifically highlight the role of intermediate species in various types of CYP-mediated oxidation reactions; these intermediate species are formed during steps of the CYP 450 catalytic cycle [78]. Oxygen concentration and $\mathrm{pH}$ are the two major factors that play an important role in CYP-mediated coupling reactions [79].

In this way, the CYP-mediated ROS-generated reaction through their catalytic cycle modifies the cellular components which lead to various diseases. It is clear how CYP dur- ing their catalytic cycle alters the redox reactions and disrupts the normal P450 catalytic cycle, which results in oxidative stress leading to development of various kinds of disease.

2.8. Mitochondrial Dysfunction and Signaling. Mitochondria regulate the urea cycle, amino acid, iron, and fat metabolism and produce energy required for the cell to perform all important functions [80-82]. In cells, the major site for the production of ROS is mitochondrion [83]. Increased levels of ROS production act as a clear death threat to the cells because it directly affects the defense mechanism, the most exclusive autophagy, and plays their role as signaling molecules which ultimately results in cell death either by autophagy or apoptotic pathway (Figure 8). In each case, mobilization of various $\mathrm{H}_{2} \mathrm{O}_{2}$ sensitive pathways is initiated [84]. Moreover, in starved conditions, autophagy process increases due to elevated ROS production by mitochondria [85].

Similar studies in obese (ob/ob) mice have also shown increased production of FFAs from glucose, elevated $\mathrm{mt}$ ROS productions, and elevated levels of triglycerides [86], higher oxidative stress due to increased lipid peroxidation while decreased hepatic mitochondrial components of MRC and decreased ATP levels [87]. All these mitochondrial changes require alterations in mitochondrial ROS levels, changes in mitophagy, biogenesis, and relevant signaling pathways of ROS.

It also requires changes in cholesterol and GSH levels in mitochondria. Changes in FFAs, lipid peroxidation products, and TNF are observed as well [88]. Oxidative stress causes ROS generation which results in the activation of cascades involving PKC $\beta$-dependent phosphorylation of pp66shc and its movement to the matrix of mitochondria, and these mitochondria are also the main target of ROS.

2.9. Serine/Threonine Kinase (AKT) Pathway. It is also known as protein kinase $B(\mathrm{PKB})$ play an important role in angiogenesis in pathological condition and tumor growth via different Ser/Thr kinase family members like liver kinase B1 (LKB1), calcium/calmodulin-dependent protein kinase IV (CAMKIV), and sulfatase (SULF2). LKB1 has multiple phenotypic expressions for the regulation of cell polarity, metabolism, proliferation, and apoptosis. In HCC, LKB1 phosphorylate at Ser428 that phosphorylates AMP-activated protein kinase (AMPK) microtubule affinity-regulating kinase (MARK) phosphorylation leads to activation and localization of cofactors like pseudokinase Ste20-related adaptor (STRAD $\alpha$ ) and the scaffolding protein MO25. The STRAD $\alpha$ and MO25 form a complex that binds with the LKB1 and relocalize it from nucleus to cytoplasm and stimulate its cell proliferation and angiogenesis [89]. Calcium $\left(\mathrm{Ca}^{+2}\right)$ regulates various biological processes as a second messenger via a variety of signaling pathways. It binds to downstream effector calmodulin (CAM) and increases the affinity toward calmodulin-kinase like $\mathrm{Ca}^{+2 \pm} / \mathrm{CAM}$-protein kinase-IV (CAMKIV). CAMKIV expression is increased in HCC and shows cell proliferation and cell cycle regulation [90].

Overexpression of calcium in HCC binds with the calmodulin that forms a complex with upregulated $\mathrm{Ca}^{+2} / \mathrm{CAM}$ dependent protein kinase kinase-2 (CAMKK2). Further, this 


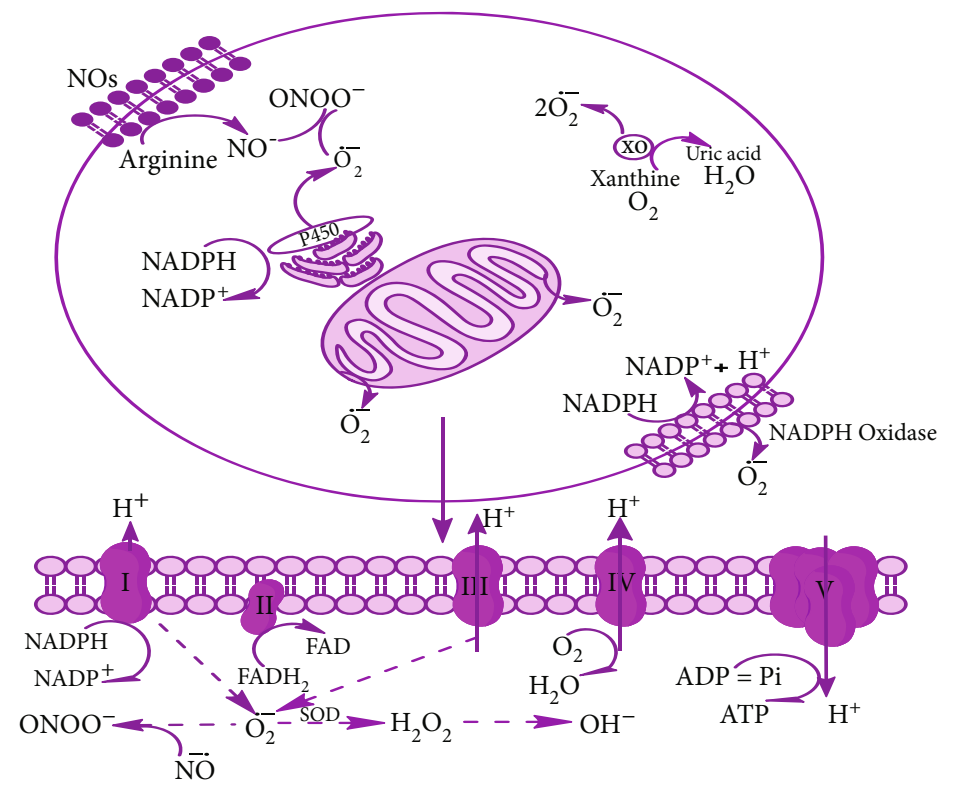

FIGURE 5: Generation of reactive oxygen species (ROS).

\section{Role of $\underline{\mathrm{CYPs}} \underline{\text { in }} \underline{\mathrm{ROS}} \underline{\text { mediated diseases }}$}

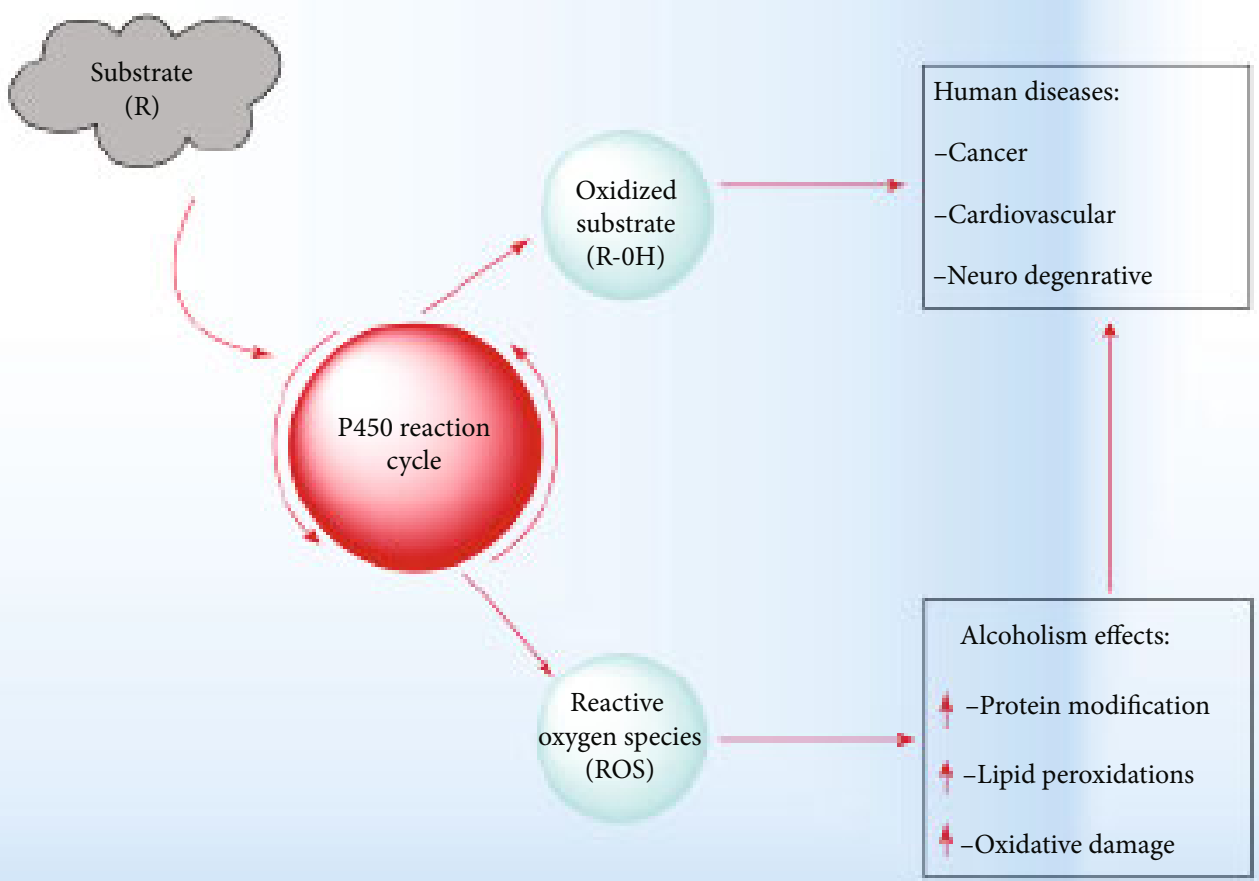

FIGURE 6: Cytochrome P450 contribution to human diseases caused by ROS and produced as a result of substrate metabolism by CYP 450s which cause elevations in protein and nucleic acid levels and cause lipid modifications. These modified products further lead to lipid peroxidation processes and also cause DNA damage which in turn causes cancer. 


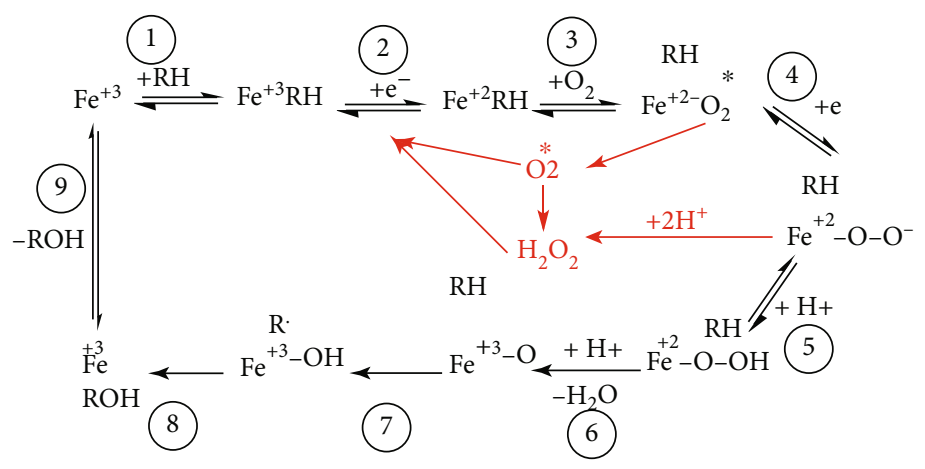

FIGURE 7: Summarized CYP 450 catalytic cycle. Catalytic cycle of P450s showing some critical steps where ROS are generated (shown in red). These ROS can further cause damage to cellular components that lead to various diseases.

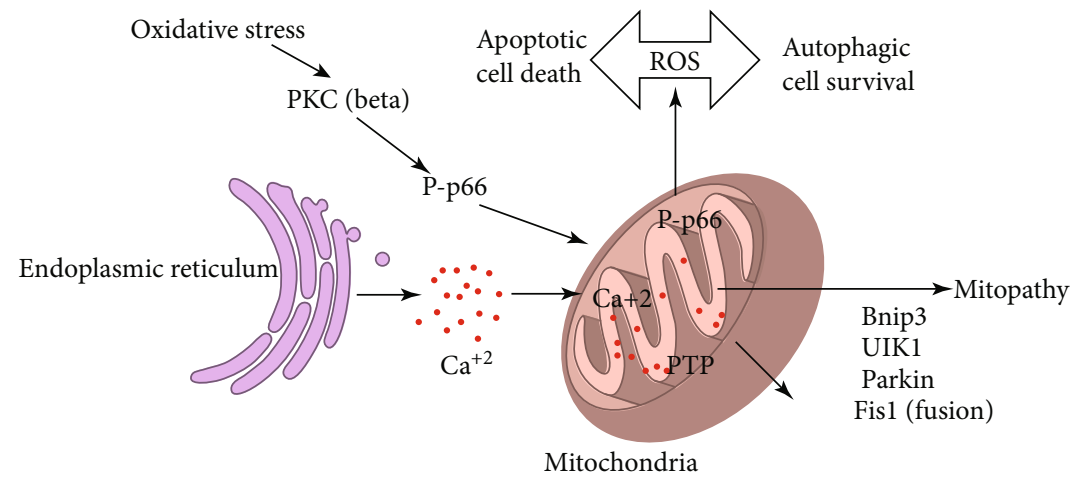

FIGURE 8: Signaling pathways regulating mitochondrial function.

complex stimulates the CAMKIV and AMPK that leads to stimulate angiogenesis [91]. Sulfatase 2 (SULF2) is elevated in HCC that is linked with increased tumor growth, hepatoblast phenotype, and a higher rate of tumor recurrence. Dephosphorylation of SULF2 enzyme leads to 6-O-desulfurase that acts on heparin sulfate proteoglycans (HSPGs) and releases the cytokines and growth factors like inflammatory mediators. These mediators regulate the SULf2-directed tumorigenesis via different pathways like hedgehog $(\mathrm{HH}), \mathrm{WNT}$, and $\mathrm{TGF} \beta$. These pathways transcripts the common pathway GLI family zinc finger 1(GLI1). SULF2-GLI1 promotes tumor growth via heterodimerization of STAT3 that work via the JAK/STAT signaling pathway as shown in Figure 9 [92]. Many signaling pathway inhibitors have been approved by the FDA or are in clinical trials (as shown in Table 1).

\section{Antioxidant Effect of Medicinal Plants}

Reactive oxygen species (ROS) is a class of reactive molecules, which are generated from oxygen metabolism [105]. Furthermore, several damages occurred in cells and tissues, not only during infections but also various degenerative disorders including cardiovascular disease, aging, neurodegenerative diseases, and cancer by ROS $[106,107]$. For radical detoxification, human cells have defense mechanisms. In these cells, superoxide dismutase (SOD) transforms superoxide into hydrogen peroxide and oxygen, then converted the $\mathrm{H}_{2} \mathrm{O}_{2}$ into water, and toxic ROS are scavenged by catalase (CAT), glutathione peroxidase $(\mathrm{GPx})$, and reduce oxygen-free radi-

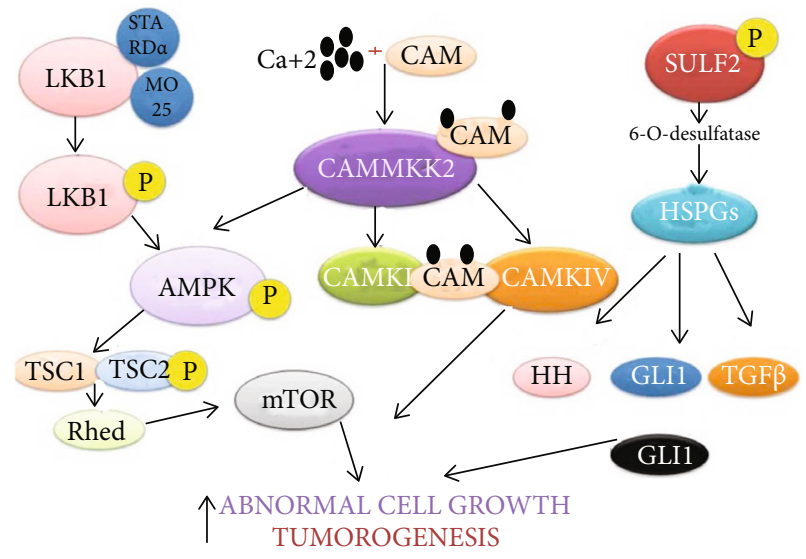

FIGURE 9: Serine/threonine kinase (AKT) pathway. LKB1: liver kinase B1; HSPGs: heparin sulfate proteoglycans; CAMKK2: Ca +2/CAM-dependent protein kinase kinase-2; CAMKIV: calcium/calmodulin-dependent protein kinase IV; SULF2: sulfatase 2; STRAD $\alpha$ : Ste20-related adaptor; HH: hedgehog; GLI1: GLI family zinc finger 1.

cals in cells. Additionally, antioxidant enzymes (SOD, CAT, and GPx), along with vitamin A, C, E play a provital role in the antioxidant defense mechanisms [108-111]. In recent years, researchers focused on the natural phytochemicals found in berry crops, teas, herbs, oilseeds, beans, fruits, and vegetables, which are the potential sources of antioxidant compounds to treat several $[19,112-119]$. 
TABLE 1: Clinical trials and FDA approved molecules that exert inhibitory effect for each signaling pathway.

\begin{tabular}{|c|c|c|c|c|c|c|}
\hline $\begin{array}{l}\text { Compounds/ } \\
\text { drugs }\end{array}$ & Chemical structure & $\begin{array}{c}\text { Clinical } \\
\text { trial/ } \\
\text { FDA } \\
\text { approved }\end{array}$ & $\begin{array}{l}\text { Receptor/ } \\
\text { target }\end{array}$ & Description & Inhibitor & References \\
\hline
\end{tabular}

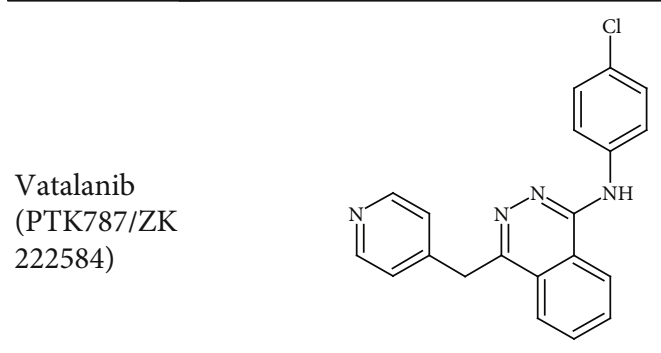

$$
\text { Vatalanib }
$$

AE-941

$\left(\right.$ Neovastat $\left.^{\circledR}\right)$

Structure not available

\begin{tabular}{|c|c|c|c|}
\hline $\begin{array}{c}\text { Phase } \\
\text {-III }\end{array}$ & $\begin{array}{l}\text { VEGFR1, } \\
\text { VEGFR2, } \\
\text { VEGFR3, } \\
\text { PDGFR- } \beta \text {, }\end{array}$ & $\begin{array}{c}\text { Small-molecule tyrosine } \\
\text { kinase receptor } \\
\text { inhibitor }\end{array}$ & $\begin{array}{l}\text { VEGF } \\
\text { signaling } \\
\text { pathway }\end{array}$ \\
\hline
\end{tabular}

VEGF

pathway

VEGF-

VEGFR-

Phase binding
-III

MMP2,

MMP9
VEGF signaling $\quad[93,94]$ pathway
VEGFR-2, Small-molecule Raf PDGFR- $\beta$, kinase and tyrosine FLT3, c-Kit
VEGF signaling pathway
Allosteric, non-ATP competitive smallmolecule inhibitors
MAPK pathway

$$
\begin{gathered}
\text { FDA } \\
\text { approved }
\end{gathered}
$$<smiles>Cn1cnc2c(F)c(Nc3ccc(Br)cc3F)c(C(=O)NOCCO)cc21</smiles>

Binimetinib
BRAF $^{\text {V600E }}$ Allosteric, non-ATP competitive smallmolecule inhibitors
MAPK pathway
Genistein

Phase I-

II
GSK3- $\beta$

$$
\begin{array}{cc}
\begin{array}{c}
\text { Inactivate Wnt } \\
\text { signaling by }
\end{array} & \begin{array}{c}
\text { Wnt } \beta \text { - } \\
\text { catenin }
\end{array} \\
\text { upregulating the } & \text { signalling } \\
\text { expression of GSK3- } \beta & \begin{array}{c}
\text { pathway } \\
\text { and E-cadherin }
\end{array}
\end{array}
$$


TABLE 1: Continued.

\begin{tabular}{|c|c|c|c|c|c|c|}
\hline $\begin{array}{l}\text { Compounds/ } \\
\text { drugs }\end{array}$ & Chemical structure & $\begin{array}{l}\text { Clinical } \\
\text { trial/ } \\
\text { FDA } \\
\text { approved }\end{array}$ & $\begin{array}{l}\text { Receptor/ } \\
\text { target }\end{array}$ & Description & Inhibitor & References \\
\hline
\end{tabular}<smiles>O=c1c(-c2ccc(O)cc2)coc2cc(O)cc(O)c12</smiles>

Genistein

PRI-724

Idelalisib<smiles>C[C@@H]1[C@@H]2N(C(=O)CN(C)N2C(=O)NCc2ccccc2)[C@H](Cc2ccc(OP(=O)(O)O)cc2)C(=O)N1Cc1cccc2cccnc12</smiles>

PRI-724<smiles>CC[C@H](Nc1ncnc2nc[nH]c12)c1nc2cccc(F)c2c(=O)n1-c1ccccc1</smiles>

Idelalisib<smiles>C[C@@H](Nc1ncnc2nc[nH]c12)c1cc2cccc(Cl)c2c(=O)n1-c1ccccc1</smiles>

Duvelisib
Blocks the interaction between $\beta$-catenin and

Phase $1 \quad \beta$-Catenin its transcriptional coactivator CREBbinding protein (CBP)
$\mathrm{Wnt} / \beta-$ catenin signalling pathway
Capable of inducing apoptosis and inhibit

USFDA approved

PI3K- $\delta$
PI3K signaling $\quad[100,101]$ pathway
Capable of inducing apoptosis and inhibit

USFDA PI3K- $\gamma$ and approved $\mathrm{PI} 3 \mathrm{~K}-\delta$
AKT phosphorylation and downstream effectors
PI3K signaling $\quad[101,102]$ pathway

Inhibits tumor cell Fibroblast differentiation, growth proliferation, factor angiogenesis pathway 
TABLE 1: Continued.

\begin{tabular}{|c|c|c|c|c|c|c|}
\hline $\begin{array}{l}\text { Compounds/ } \\
\text { drugs }\end{array}$ & Chemical structure & $\begin{array}{c}\text { Clinical } \\
\text { trial/ } \\
\text { FDA } \\
\text { approved }\end{array}$ & $\begin{array}{c}\text { Receptor/ } \\
\text { target }\end{array}$ & Description & Inhibitor & References \\
\hline
\end{tabular}<smiles>COc1cc(OC)cc(N(CCNC(C)C)c2ccc3ncc(-c4cnn(C)c4)nc3c2)c1</smiles>

Netarsudil

\section{Oxidative Stress Associated with HCC}

Oxidative stress happens once there is an associate degree imbalance between reactive chemical element species (ROS) generation and attenuated by antioxidant enzymes or compounds. Excessive production of ROS will cause aerophilous harm to biomacromolecules leading to supermolecule peroxidation and carcinogenesis $[120,121]$.

Anticancer medication increases malondialdehyde (MDA) level and decreases inhibitor enzymes like GPx, GR, CAT, SOD, and GSH $[122,123]$. They increase (MDA) and XO level, cytokines TNF- $\alpha$, IL-6, i-NOS, cyclooxygenase-2, and P38-MAPK, NF- $\kappa \mathrm{B}$, and generation of ROS and RNS (reactive nitrogen species) in a viscous cell $[124,125]$. In ethanol, the cytoplasm and mitochondria are reborn aldehyde and acetate by vasoconstrictive, ALDH, $\mathrm{NAD+}$, and $\mathrm{NADH}$, which may increase ROS generation in the liver cell, cause DNA harm, mitochondrial pathology, lipid peroxidation, supermolecule denaturation, and stimulate many viscous sicknesses as well as steatosis, fibrosis, cirrhosis, steatohepatitis, and carcinoma [126].

Ordinarily, ROS and RNS are generated by strongly bound enzymes. Too much stimulation of $\mathrm{NAD}(\mathrm{P}) \mathrm{H}$ and negatron transport chain results in the production of ROS, which leads to stress and can injure the cell structures, lipids, proteins, and DNA. The production of ROS by vegetative cells was originally referred to as "the metabolism burst" because of the redoubled consumption of chemical elements by these cells. This method is catalyzed by $\mathrm{NAD}(\mathrm{P}) \mathrm{H}$ enzyme and is important for the disinfectant action of phagocytes [127]. The metabolism of organic compounds (L-arginine) forms $\mathrm{NO}$ - free radicals. The gas synthase (NOS) enzymes are catalyzing the process, and through 5 electron oxidization of a guanidine gas of $\mathrm{L}$-arginine, it converts L-arginine into L-citrulline and $\mathrm{NO} \bullet$ radical [128].

\section{Potential of Phytochemicals}

5.1. Scavenging of ROS. In any kind of cancer, lethal effects due to oxidative stress can be harmful. To counterbalance this, antioxidant mechanisms in normal human cells should be needed [129]. Besides, it can be considered as a significant process that is taken by phytoconstituents to prevent cancer (Table 2).

The scavenging process is done by different antioxidant mechanisms so that they could not be able to cause any disfigurement. Some nonradical and radical ions that work as ROS are hydrogen peroxide $\left(\mathrm{H}_{2} \mathrm{O}_{2}\right)$, superoxide radical $\left(\mathrm{O}_{2}{ }^{-}\right)$, hydroxyl radical (.OH), and peroxyl radical (ROO.). Protein, DNA, and lipids are excessively harmed due to these ions and also altered the regular cellular functioning system. Some phytochemicals act as antioxidant or prooxidant whose modulators are mainly guided by two factors, one is the microenvironment and another is the concentration of ROS present within the cells. To keep a healthy balanced metabolic activity, the proper quantity of ROS in normal cells is necessary. Now, cells can be damaged through oxidative stress, especially when ROS comes from extrinsic sources. Normal cells can be injured by external factors. In this case, phytoconstituents can play an important role as antioxidants to protect those cells from damage [171].

5.2. Phytochemicals Evaluation in Clinical Trials. Phytochemicals derived from medicinal herbs that are now clinically tested and used in the treatment of liver fibrosis are Inchin-ko-to (TJ-135), Yi Guan Jian, Fufang-Liu-Yue-Qing, and DangguiBuxue Tang [172-175]. An enormous number of anticancer compounds, which are now in progress, nevertheless lead to clinical studies in their initial phases. Through various preclinical researches, the efficacy of different 


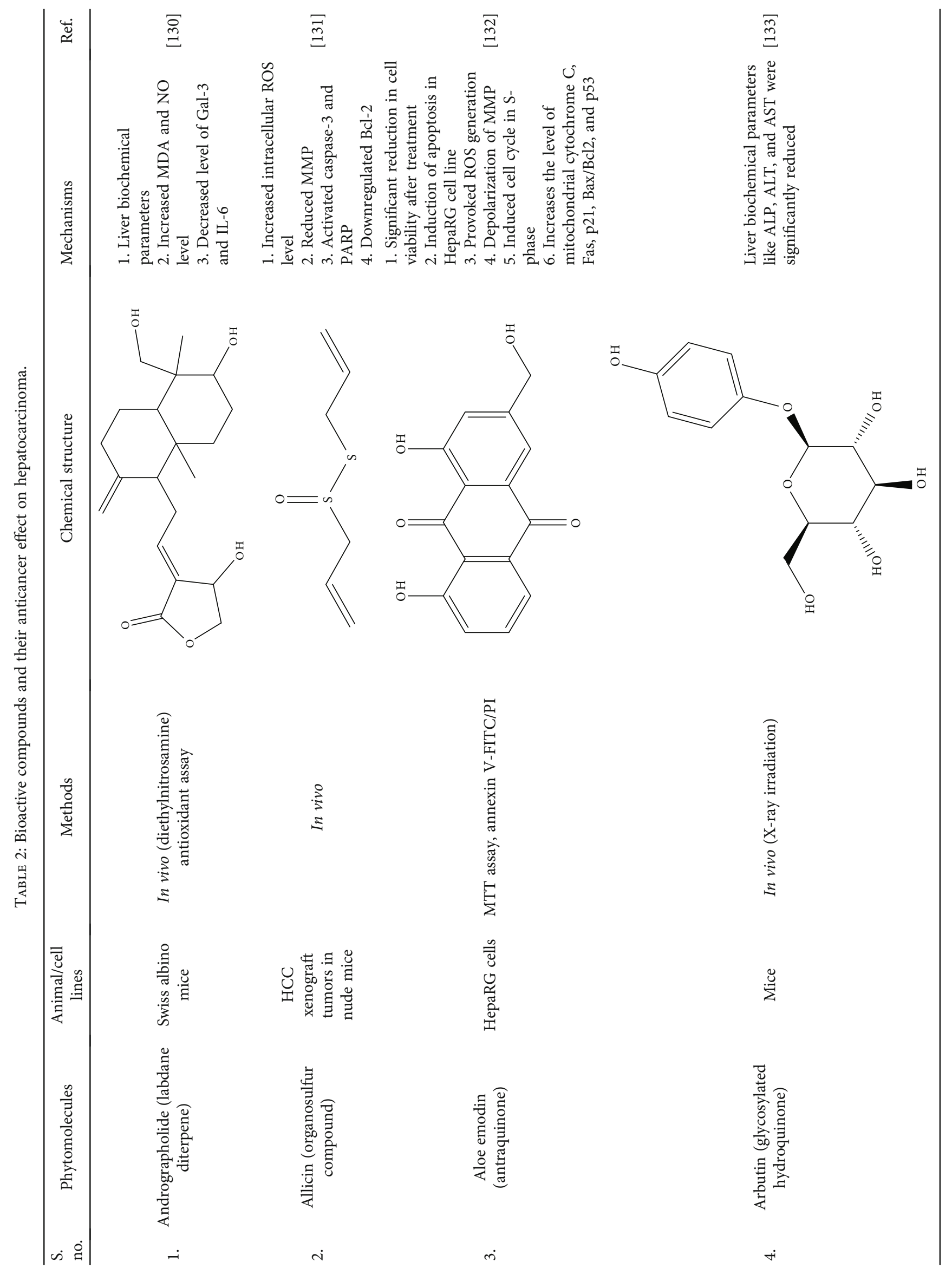




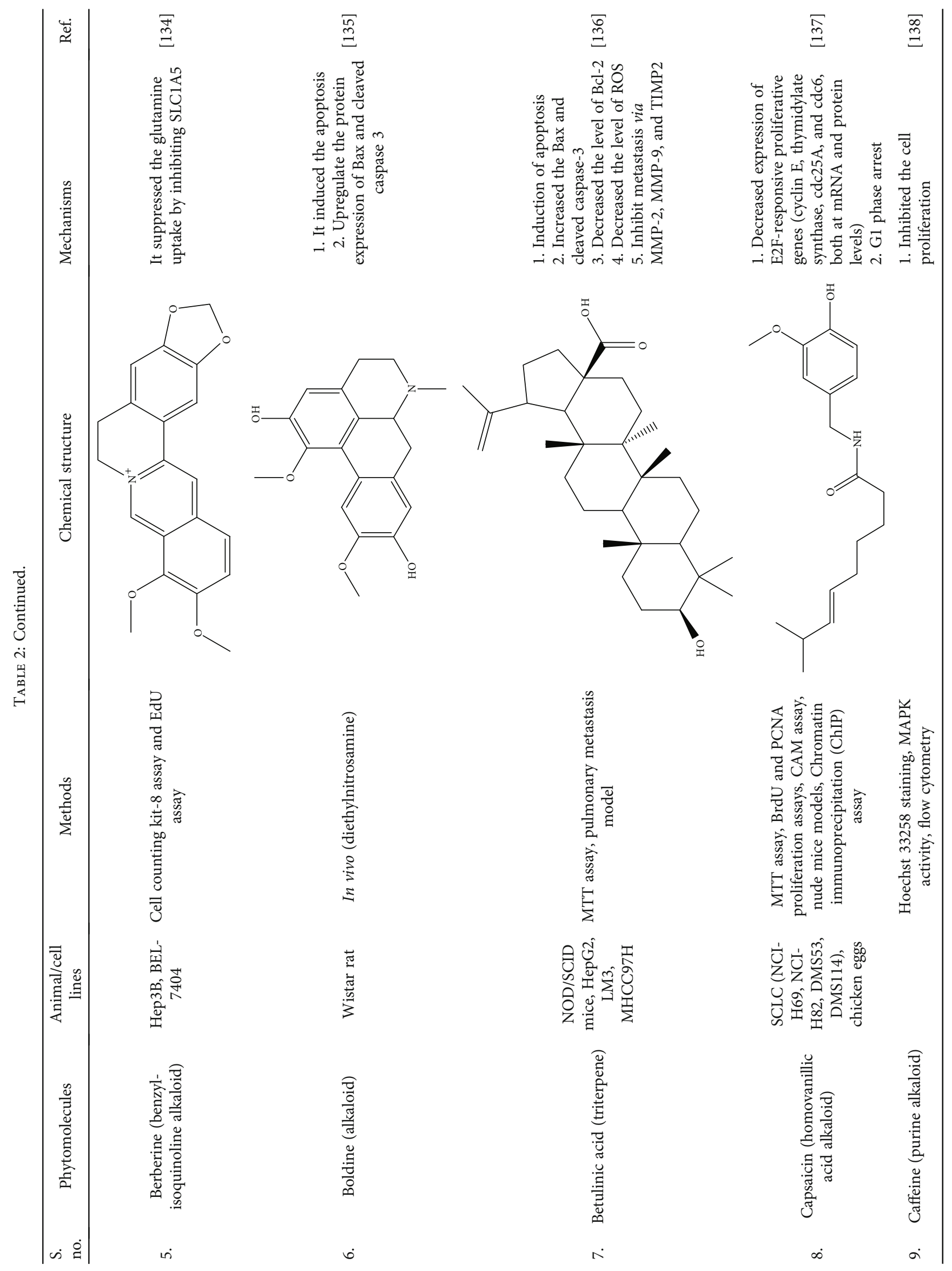



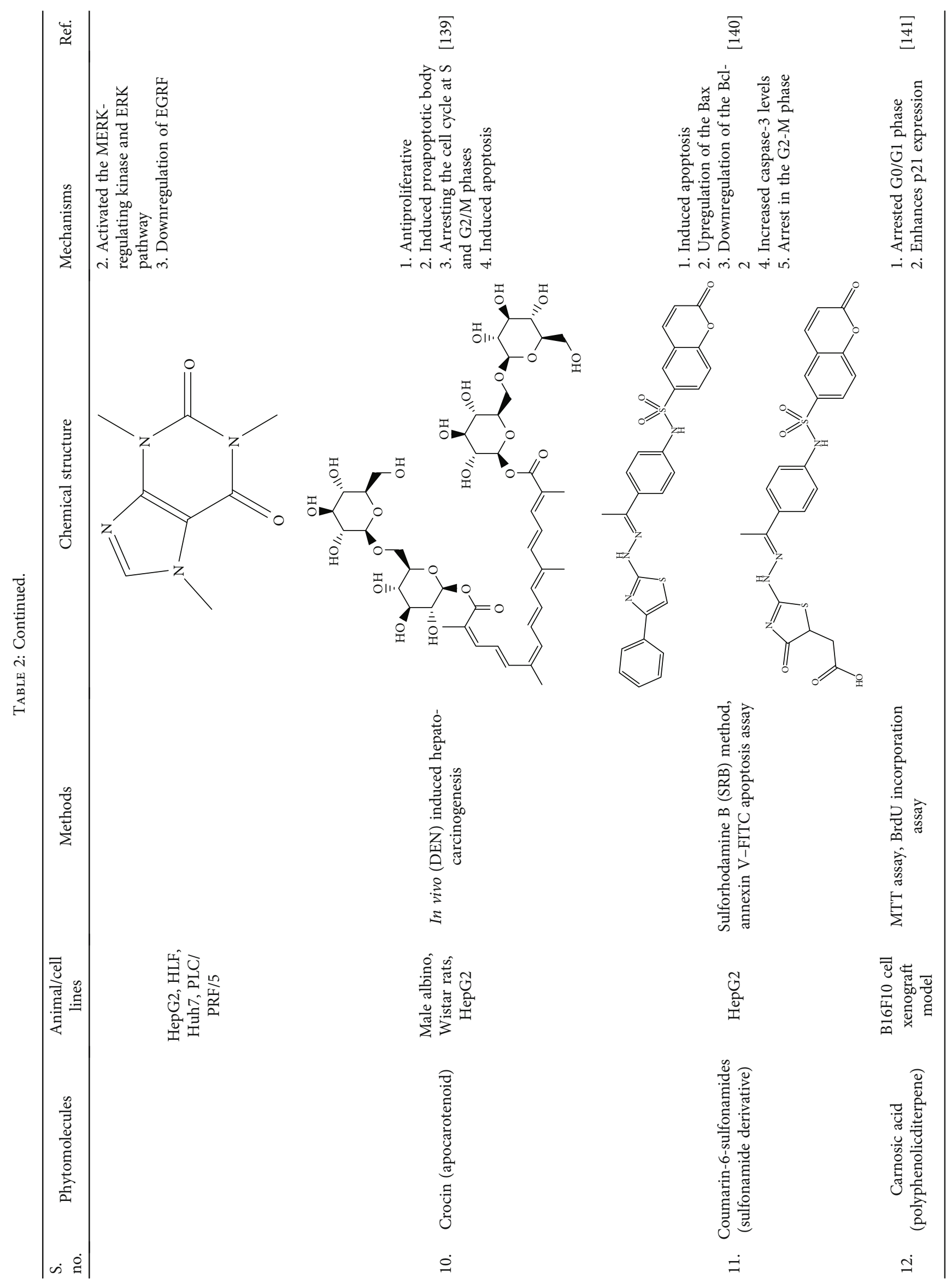


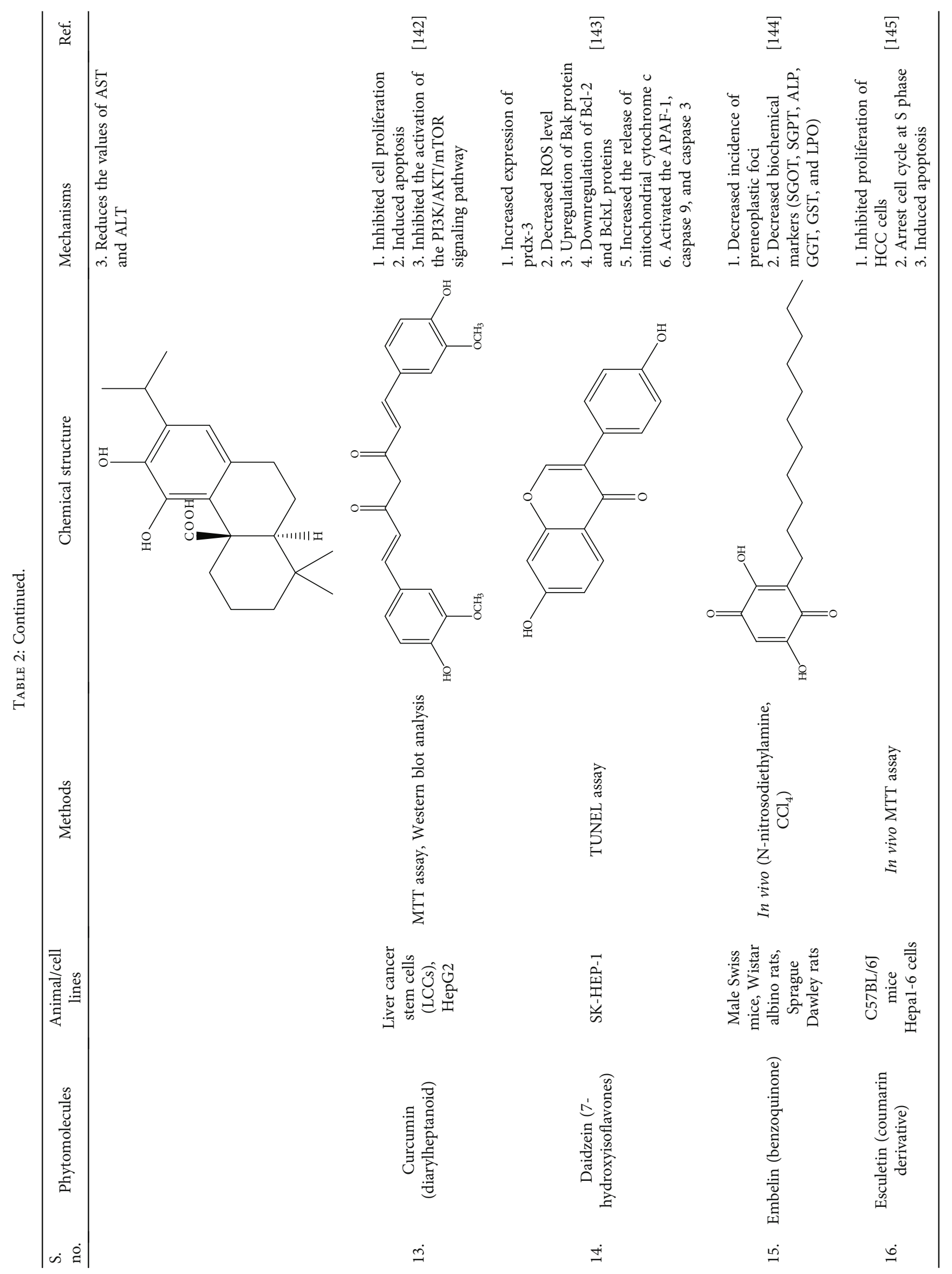




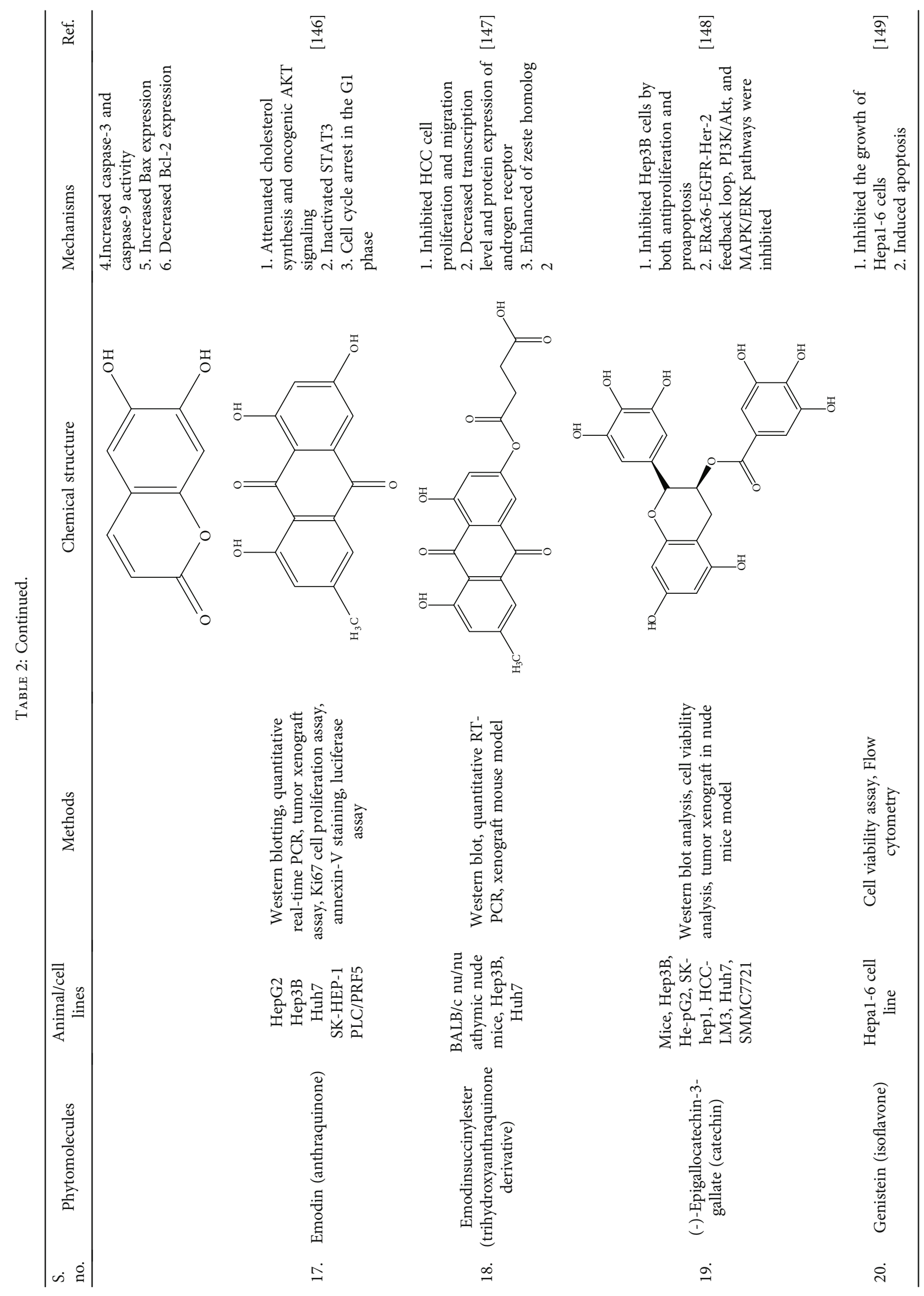




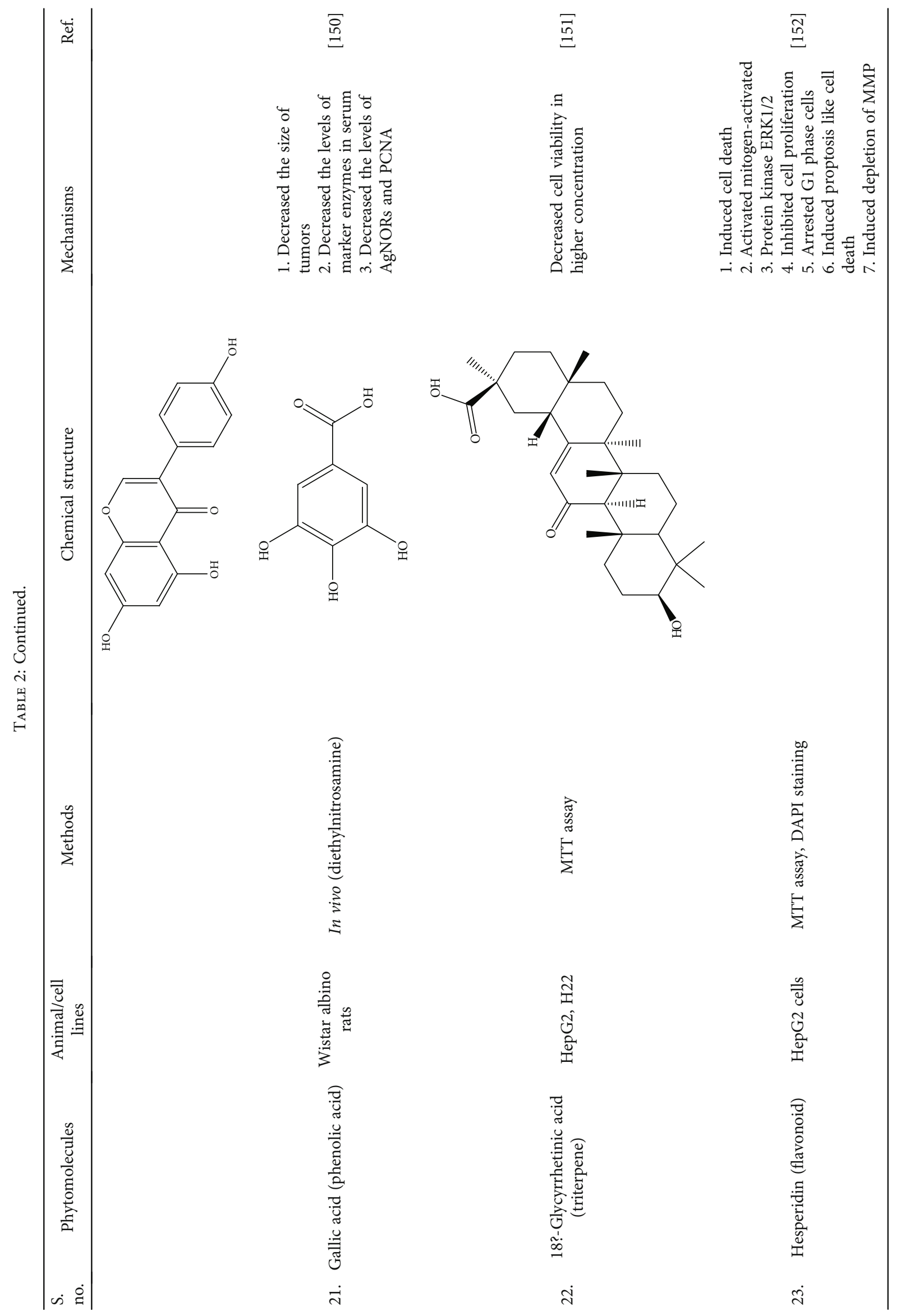



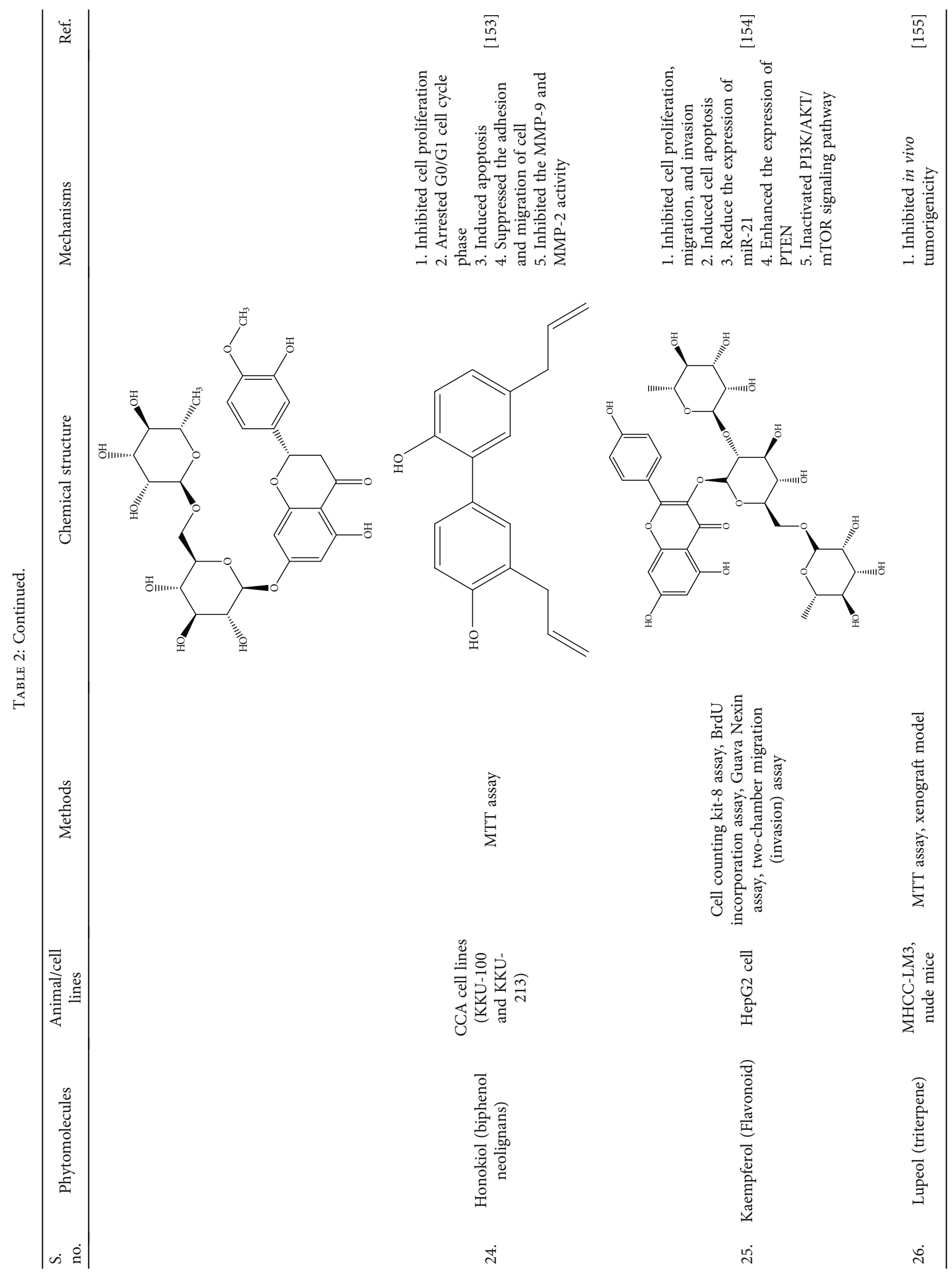

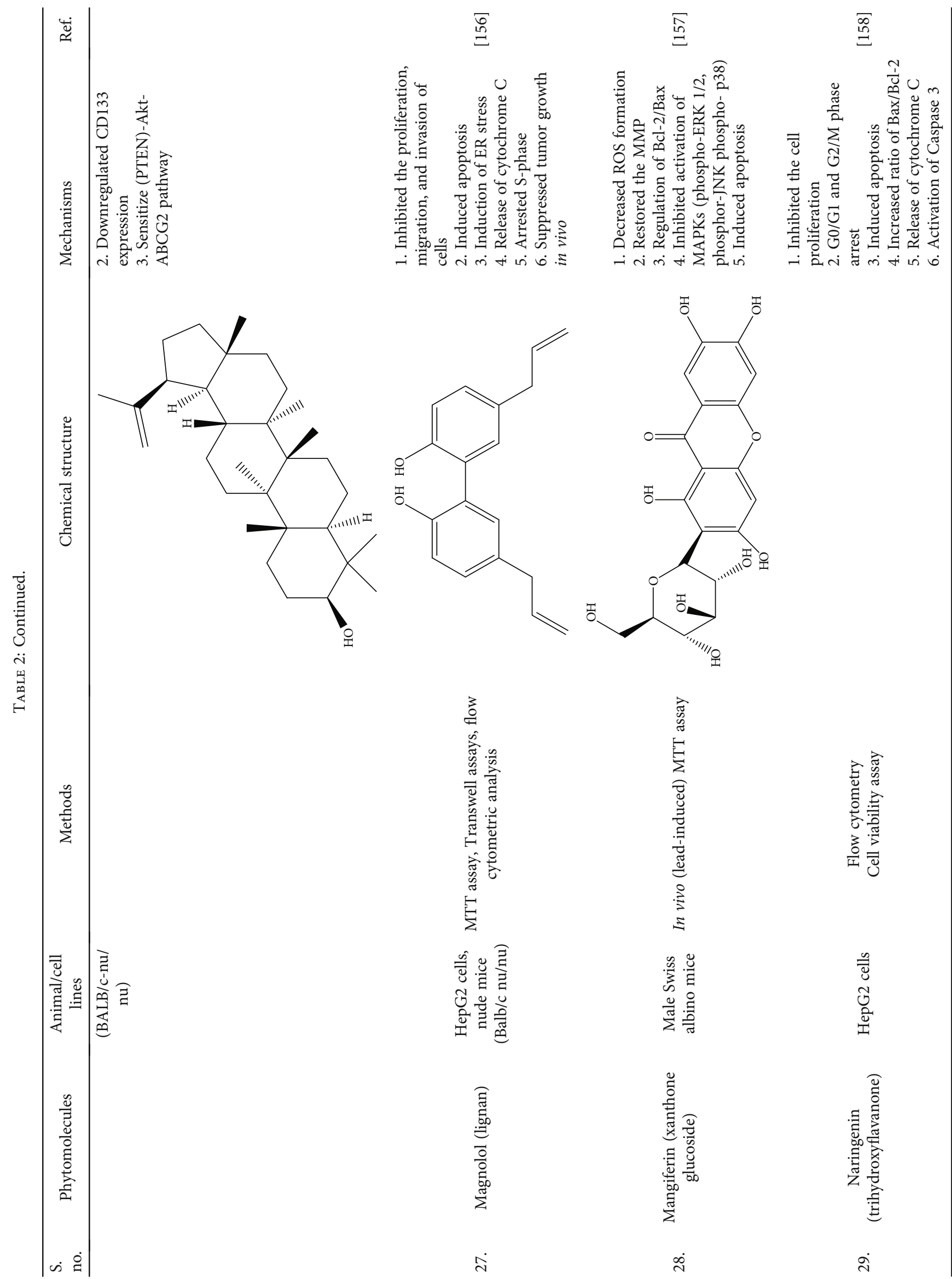

งิ

을

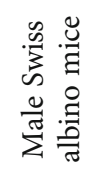

चี
సै
:
:

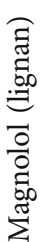

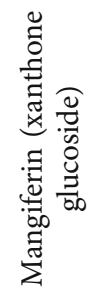

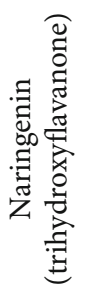

ลิ่

$\stackrel{\infty}{\sim}$

ล่ 

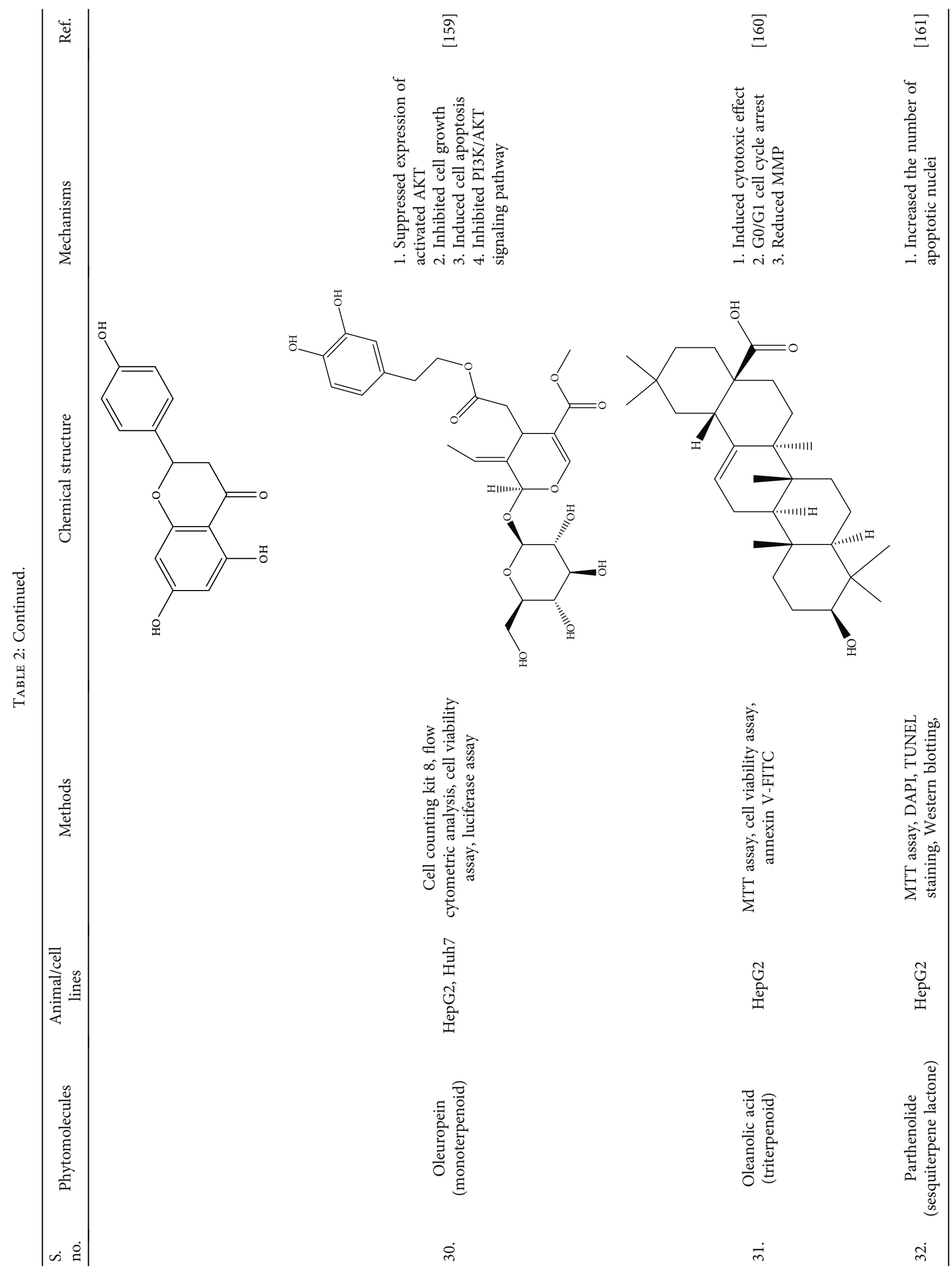

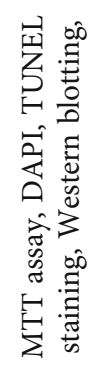

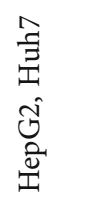

ปั
जิ
ज्ञ
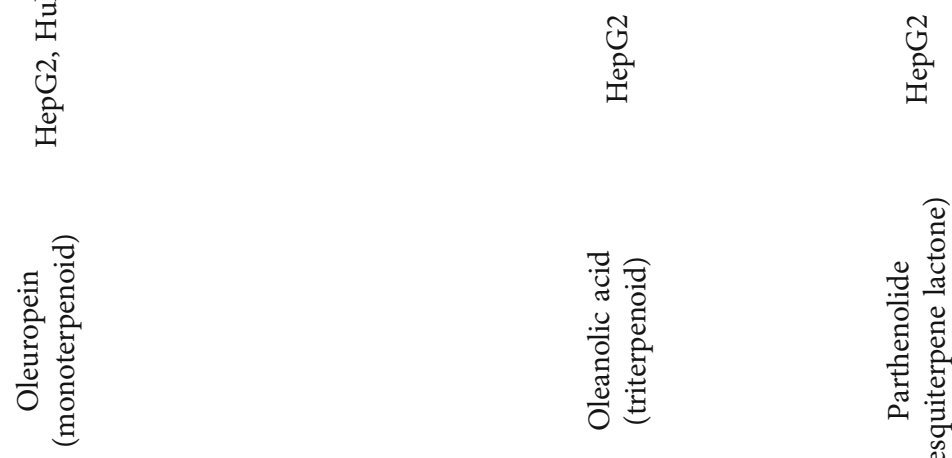

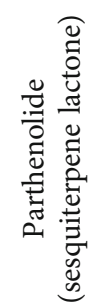

$\dot{m}$

$\dot{m}$

ก் 

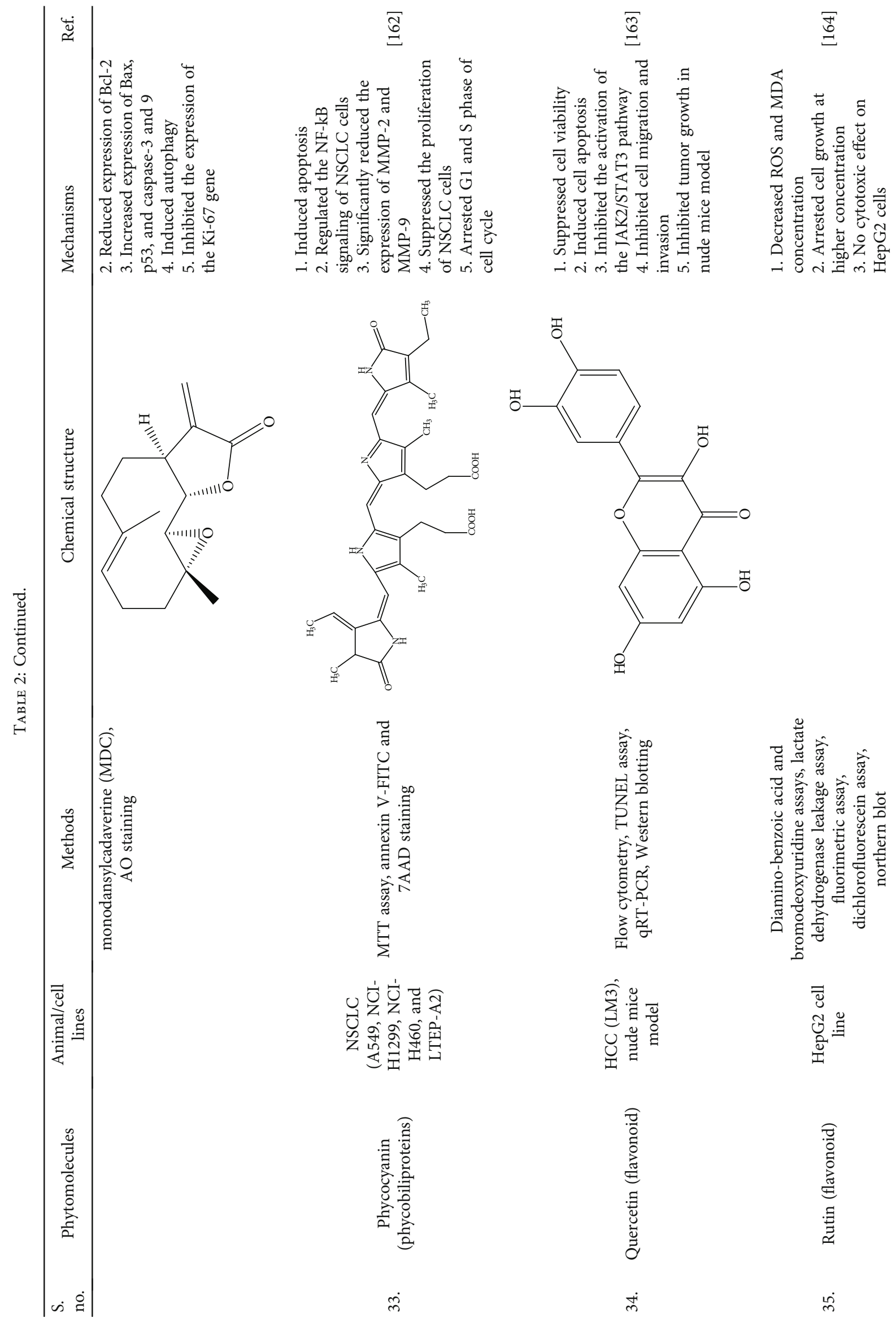

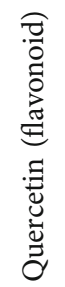

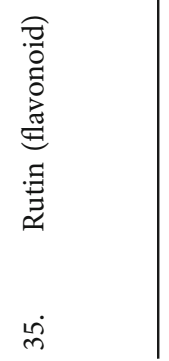

$\dot{m}$

में

m 


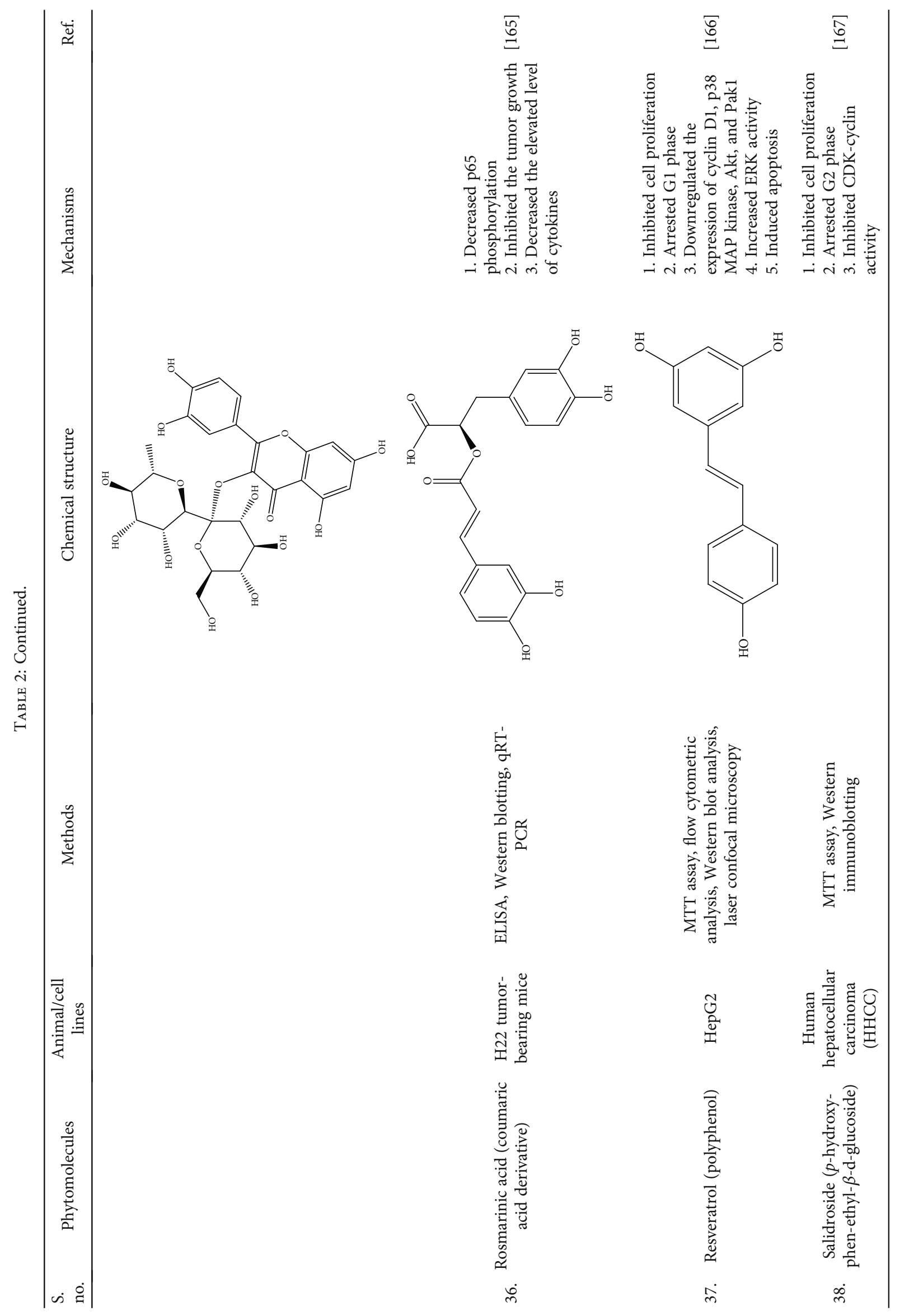



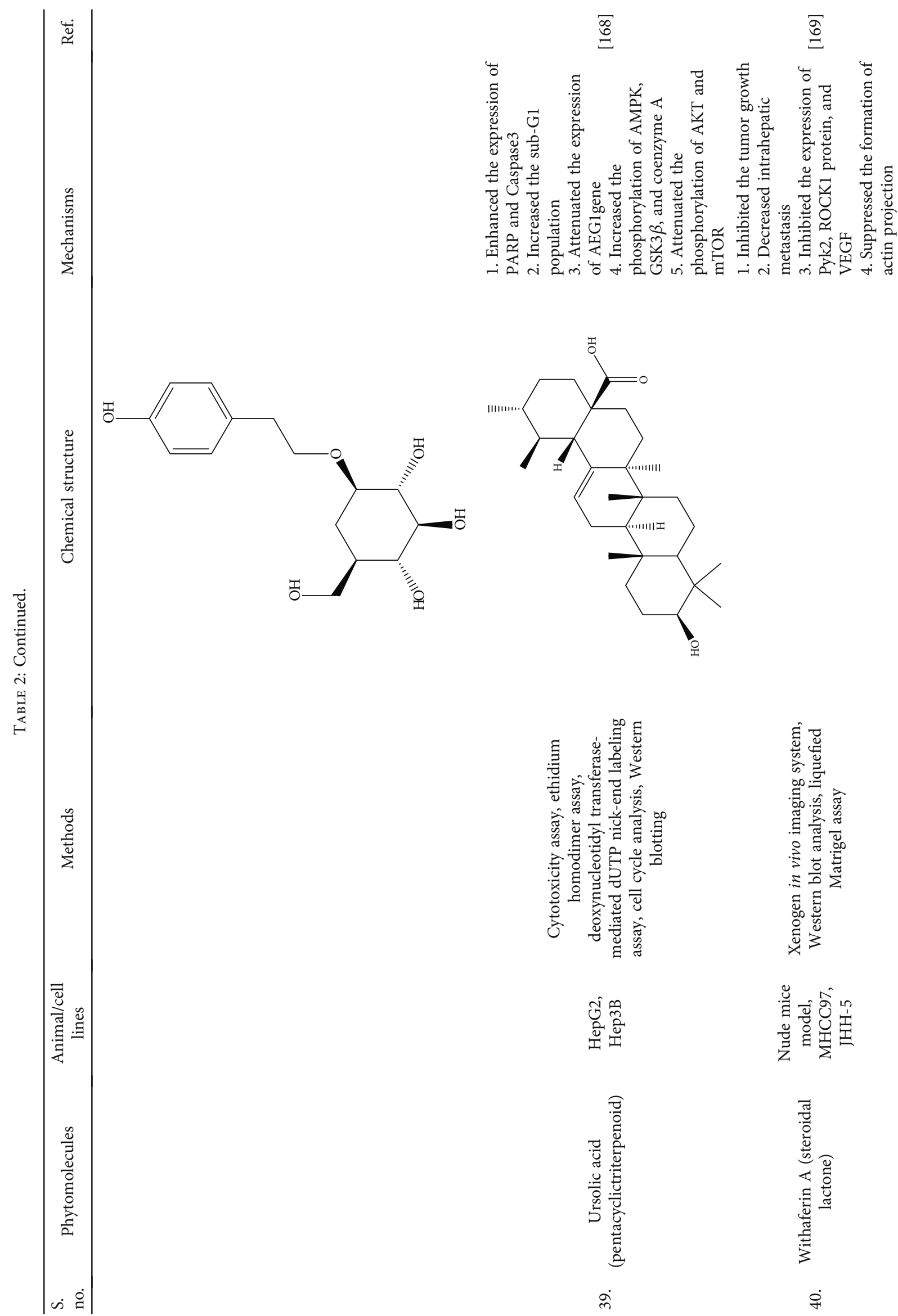

कें

워 

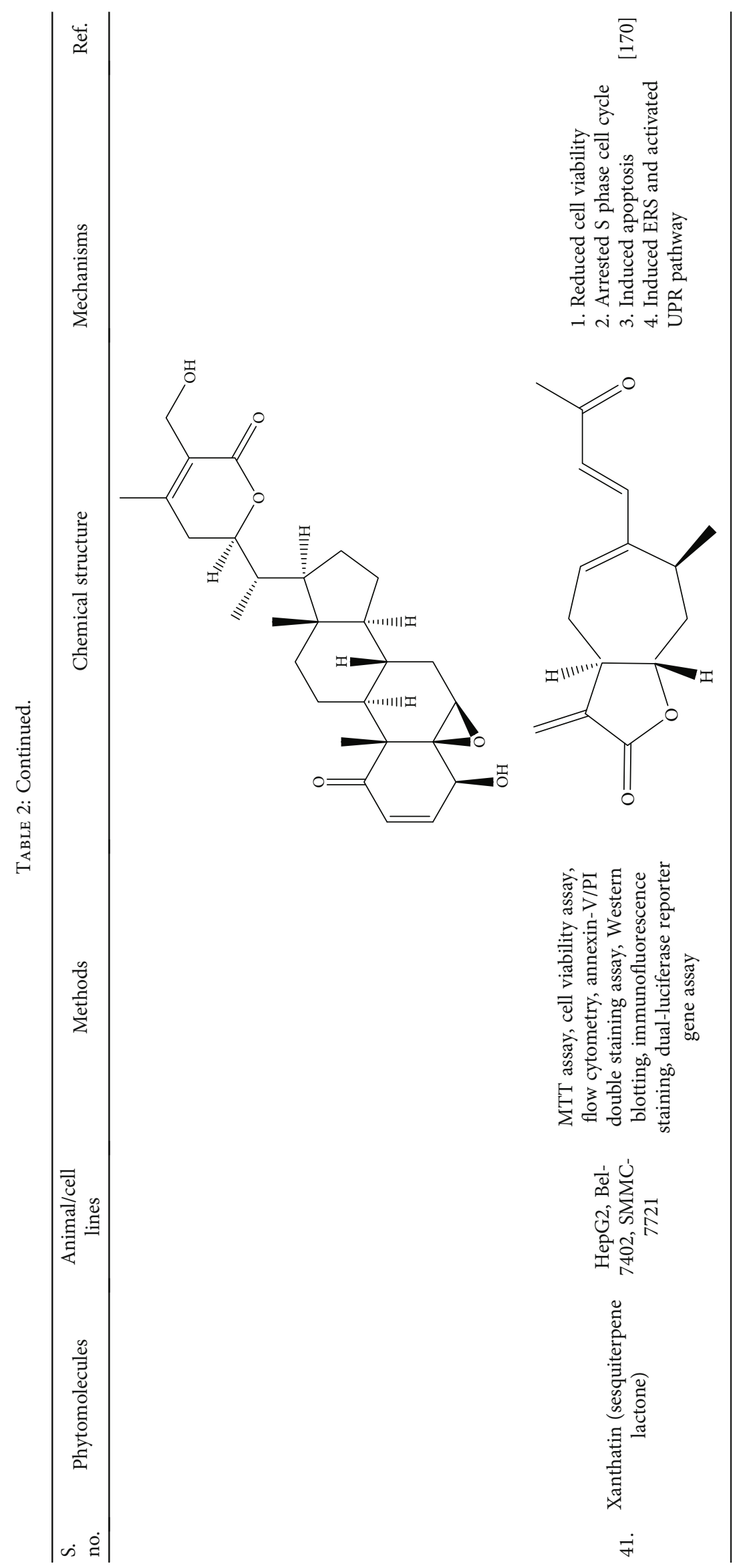
phytochemicals has represented such as, andrographolide, berberine, capsaicin, curcumin, genistein, ursolic acid, and withaferin A.

Andrographolide restrains tumor development by obstructing tumor adjustment to hypoxic conditions. The detected effects of andrographolide $(100 \mathrm{mg} / \mathrm{kg})$ were attributed to the restriction of the hypoxia-inducible figure (HIF) [176]. The recovery rate of different myeloma patients has made strides through the use of andrographolide in a clinical trial $[177,178]$. While investigations are undertaken via the large quantity of information on preclinical efficacy, clinical studies are limited in the evaluation of berberines and andrographolide genuine potential as a carcinoma operator [179].

Capsaicin supplementation significantly reduced the establishment of preneoplastic foci in a rat model of hepatocarcinogenesis caused by diethylnitrosamine, HCC cell lines were likewise stopped from proliferating, and apoptosis was triggered on a dose-based manner [180, 181]. Furthermore, HCC cells were shown to be more sensitive than normal hepatocytes to capsaicin induced cytotoxicity suggesting that it might have a chemotherapeutic effect [182].

Curcumin is a chemopreventive agent with a lot of optimism. This has prompted clinical practices to investigate the pharmacokinetics and effectiveness of curcumin in patients. It was shown to be safe and nontoxic in phase I clinical studies, even at large dosages ( $8 \mathrm{~g} /$ day). However, it had limited absorption individuals $[183,184]$. Their clinical trials, either alone or as anticancer agent combinations, demonstrated efficacy, despite challenges to bioavailability, in several disease sites [185-187].

The medication with genistein $(140 \mathrm{mg} / \mathrm{kg})$ is by preventing aberrant nuclear $\beta$-catenin harvests and concealing WNT signaling features [188]. Ursolic acid (UA) was represented to upgrade the restorative impacts of oxaliplatin in the mouse model of CRC by restraining the tumor and expanding the survival rate. Tumor shape is lessened by the UA nanoparticles by focusing on caspases and p53 with downregulation of $\mathrm{Bcl}-2$ and cIAP, instigating apoptosis and driving to cervical cancer cell distortion [189], whereas the tumor development of human colorectal carcinoma (HCT-116) cells which overexpress AKT and microvessel arrangement is hindered through the verbal organization of Withaferin A $(5 \mathrm{mg} / \mathrm{kg})$ in a mouse model [190].

5.3. Detoxification of Enzymes. Xenobiotic compounds are responsible for putting impacts on humans affecting tissues. To lessen that impact, there are several responses or potentials [191]. Among them, the initialization of some detoxifying enzymes is important, especially for the liver [192]. Detoxified enzymes can be induced by antioxidative phytochemicals found in plants. These phytochemicals mainly target antioxidant response or electrophile response elements (ARE/EpRE) to modulate the molecular pathways. These pathways mainly depend on three main components like ARE, nuclear factor erythroid 2 p45related factors 2 (Nrf2), and Kelchlike ECH-associated protein 1 (Keap1) [193].

TABLE 3: Medicinal plants and their bioactive compounds used in radiotherapy and chemotherapy.

Plants as radioprotector/radiosensitizer in HCC

Amaranthus

paniculatus Linn.

Coronopus didymus

(L.)

Grewia asiatica L.

Glycyrrhiza glabra L.

Hypericum

perforatum L.

Pilea microphylla (L.) Liebm.

Rosmarinus officinalis L.

Xylopia aethiopica (Dunal) A.Rich.

Bioactive phytomolecules as adjunct with chemotherapy

Curcumin

Quercetin

Ginsenosides

Decreases the depleted level of endogenic antioxidant enzymes during radiotherapy of mice liver.

Enhance the level of antioxidant enzymes in the liver of mice.

Augmented the SOD, CAT, and GSH levels in the liver of irradiated mice.

It protected plasmid DNA and reduced the liver microsomal LPO level in rat from irradiation.

In vitro and in vivo studies show the increased level of SOD, CAT, GSH-Px, and GSH during radiation therapy

Increased level of endogenous antioxidant enzyme levels in the liver of mice.

Augmented the SOD, CAT, and GSH

levels in blood and liver of mice during the radiation therapy.

Protect the liver of rat from $\gamma$-radiation

Used as an adjuvant with vinorelbine chemotherapy and enhances the antiproliferative effect of drugs.

Used as an adjunct in doxorubicin, busulfan, and cisplatin chemotherapy. It also increased cytotoxic effects of these drugs and protect from drug-induced nephrotoxicity.

Used as an adjunct with cisplatin and 5FU chemotherapy and enhanced antiproliferative effect.

5.4. Modification of Genomic Stability. Phytochemicals targets both DNA repair and their damage mechanism, where genomic stability within cells plays an important role. Besides, this genomic stability also helps a lot when chemopreventive agents trigger a selective number of cancer cells [194, 195]. There are some therapeutic agents which generate the DNA repair pathways in normal cells to modulate the stress conditions within the cells. In a contradicting way, DNA damage response can also be increased when cancer cells are exposed in a large number. As a result, apoptosis can happen, and cells can be dead permanently [196].

5.5. Cancer Cell Metabolism. Cell metabolism in tumors plays an important role in the stimulation process in protooncogenes by involving ROS production $[197,198]$. The survival and growth rate of tumor cells largely depend on their metabolic requirements which are adjusted by themselves [199]. Energy requirements are supplied by glucose, and thus, it initiates tumor growth. Besides glucose, glutamine also plays an important role in tumor growth by providing nitrogen for the biosynthesis process. Phytochemicals can 
obstruct basal transport of glucose [200], e.g., curcumin can convert glucose to glutathione [201].

5.6. Chemotherapy and Radiotherapy Enhancers. Cancer and complications that are associated with it are treated by chemotherapy and radiotherapy for decades. Radiotherapy began in the twentieth century before chemotherapy, as the primary treatment of cancer. Approximately $8 \%$ of total cancer patients need radiotherapy, but unfortunately, it causes acute toxicity even at low doses of radiation. To overcome these side effects and prevention of resistance to chemotherapy, a promising new approach is developed by the scientist by using the medicinal plant-derived drugs like taxol to combat against cancer; many researches is going on radioprotectors and radiosensitizers [202]. Radioprotectors are the compounds that are used to protect the normal cell during radiotherapy sessions; on the other hand, radiosensitizers are the molecule that is used to sensitize the tumor cell and increases the efficiency of cancer therapy. Some plants like Pilea microphylla act as a radioprotector and prevent the depleting SOD, GSH, CAT, and thiol levels during the radiotherapy in HCC. Table 3 shows the effect of medicinal plants and their bioactive compounds in chemotherapy and radiotherapy [203-206].

\section{Conclusion and Future Perspective}

The scavenging property of plant-derived bioactive compounds should be the pathway to treat HCC as they block the propagation stage in oxidative chain reactions. Furthermore, these compounds inhibit cancer cell growth and act as potent anticancer agents via different cellular and molecular mechanisms. At present, a plethora of kinase inhibitors against specific molecular targets are being investigated in HCC, which initiate differential networks that consequently result in HCC cell cycle promotion. It offers hope that other effective therapies will eventually be developed.

\section{Data Availability}

The data used to support the findings of this study are available from the corresponding author upon request.

\section{Conflicts of Interest}

There are no conflicts of interest to declare.

\section{References}

[1] M. Von Meyenfeldt, "Cancer-associated malnutrition: an introduction," European Journal of Oncology Nursing, vol. 9, pp. S35-S38, 2005.

[2] H. Van Zandwijk, G. Reid, and A. L. Frank, "Asbestos-related cancers: the 'Hidden Killer' remains a global threat," Expert Review of Anticancer Therapy, vol. 20, no. 4, pp. 271-278, 2020.

[3] S. Darvesh, A. B. Aggarwal, and A. Bishayee, "Curcumin and liver cancer: a review," Current Pharmaceutical Biotechnology, vol. 13, no. 1, pp. 218-228, 2012.
[4] F. X. Bosch, J. Ribes, M. Díaz, and R. Cléries, "Primary liver cancer: worldwide incidence and trends," Gastroenterology, vol. 127, no. 5, pp. S5-S16, 2004.

[5] M. E. Norhaizan, S. K. Ng, M. S. Norashareena, and M. A. Abdah, "Antioxidant and cytotoxicity effect of rice bran phytic acid as an anticancer agent on ovarian, breast and liver cancer cell lines," Malaysian journal of nutrition, vol. 17, no. 3, 2011.

[6] G. S. Oh, H. O. Pae, H. Oh et al., "In vitro anti-proliferative effect of 1, 2, 3, 4, 6-penta-O-galloyl-beta-D-glucose on human hepatocellular carcinoma cell line, SK-HEP-1 cells," Cancer Letters, vol. 174, no. 1, pp. 17-24, 2001.

[7] Y. L. Hsu, P. L. Kuo, C. Y. Cho et al., "Antrodiacinnamomea fruiting bodies extract suppresses the invasive potential of human liver cancer cell line PLC/PRF/5 through inhibition of nuclear factor $\kappa \mathrm{B}$ pathway," Food and Chemical Toxicology, vol. 45, no. 7, pp. 1249-1257, 2007.

[8] S. L. Yan, C. Y. Huang, S. T. Wu, and M. C. Yin, "Oleanolic acid and ursolic acid induce apoptosis in four human liver cancer cell lines," Toxicology in Vitro, vol. 24, no. 3, pp. 842-848, 2010.

[9] A. Ito, H. Watanabe, and N. Basaran, "Effects of soy products in reducing risk of spontaneous and neutron-induced livertumors in mice," International Journal of Oncology, vol. 2, no. 5, pp. 773-776, 1993.

[10] X. G. Wu, D. H. Zhu, and X. Li, "Anticarcinogenic effect of red ginseng on the development of liver cancer induced by diethylnitrosamine in rats," Journal of Korean Medical Science, vol. 16, p. S61, 2001.

[11] M. Zabala, J. J. Lasarte, C. Perret et al., "Induction of immunosuppressive molecules and regulatory $\mathrm{T}$ cells counteracts the antitumor effect of interleukin-12-based gene therapy in a transgenic mouse model of liver cancer," Journal of Hepatology, vol. 47, no. 6, pp. 807-815, 2007.

[12] S. Demir, I. Turan, and Y. Aliyazicioglu, "Selective cytotoxic effect of Rhododendron luteum extract on human colon and liver cancer cells," Journal of the Balkan Union of Oncology, vol. 21, no. 4, pp. 883-888, 2016.

[13] S. Grabley and R. Thiericke, Drug Discovery from Nature, Springer Science \& Business Media, 1998.

[14] J. M. Pezzuto, "Plant-derived anticancer agents," Biochemical Pharmacology, vol. 53, no. 2, pp. 121-133, 1997.

[15] J. Uzoigwe and E. R. Sauter, "Cancer prevention and treatment using combination therapy with plant-and animalderived compounds," Expert Review of Clinical Pharmacology, vol. 5, no. 6, pp. 701-709, 2012.

[16] T. L. Simmons, E. Andrianasolo, K. McPhail, P. Flatt, and W. H. Gerwick, "Marine natural products as anticancer drugs," Molecular Cancer Therapeutics, vol. 4, no. 2, pp. 333-342, 2005.

[17] N. Sithranga Boopathy and K. Kathiresan, "Anticancer drugs from marine flora: an overview," Journal of oncology, vol. 2010, Article ID 214186, 18 pages, 2010.

[18] G. M. Cragg, P. G. Grothaus, and D. J. Newman, "Impact of natural products on developing new anti-cancer agents," Chemical Reviews, vol. 109, no. 7, pp. 3012-3043, 2009.

[19] V. Sharma and P. Janmeda, "Protective assessment of Euphorbia neriifolia and its isolated flavonoid against Nnitrosodiethylamine-induced hepatic carcinogenesis in male mice: a histopathological analysis," Toxicology International, vol. 21, no. 1, p. 37, 2014.

[20] T. Choedon, S. K. Shukla, and V. Kumar, "Chemopreventive and anti-cancer properties of the aqueous extract of flowers 
of Butea monosperma," Journal of Ethnopharmacology, vol. 129, no. 2, pp. 208-213, 2010.

[21] J. S. Yoon, H. M. Kim, A. K. Yadunandam et al., "Neferine isolated from Nelumbo nucifera enhances anti-cancer activities in Hep3B cells: molecular mechanisms of cell cycle arrest, ER stress induced apoptosis and antiangiogenic response," Phytomedicine, vol. 20, no. 11, pp. 1013-1022, 2013.

[22] E. Brâkenhielm, R. Cao, and Y. Cao, "Suppression of angiogenesis, tumor growth, and wound healing by resveratrol, a natural compound in red wine and grapes," The FASEB Journal, vol. 15, no. 10, pp. 1798-1800, 2001.

[23] I. Ali and D. P. Braun, "Resveratrol enhances mitomycin Cmediated suppression of human colorectal cancer cell proliferation by up-regulation of p21WAF1/CIP1," Anticancer Research, vol. 34, no. 10, pp. 5439-5446, 2014.

[24] D. L. Aminin, E. S. Menchinskaya, E. A. Pisliagin, A. S. Silchenko, S. A. Avilov, and V. I. Kalinin, "Anticancer activity of sea cucumber triterpene glycosides," Marine Drugs, vol. 13, no. 3, pp. 1202-1223, 2015.

[25] I. Yıldırım and T. Kutlu, "Anticancer agents: saponin and tannin," International Journal of Biological Chemistry, vol. 9, pp. 332-340, 2015.

[26] X. B. Sun, S. M. Wang, T. Li, and Y. Q. Yang, “Anticancer activity of linalool terpenoid: apoptosis induction and cell cycle arrest in prostate cancer cells," Tropical Journal of Pharmaceutical Research, vol. 14, no. 4, pp. 619-625, 2015.

[27] D. M. Parkin, F. Bray, J. Ferlay, and P. Pisani, "Estimating the world cancer burden: Globocan, 2000," International Journal of Cancer, vol. 94, no. 2, pp. 153-156, 2001.

[28] H. B. El-Serag and A. C. Mason, "Rising incidence of hepatocellular carcinoma in the United States," New England Journal of Medicine, vol. 340, no. 10, pp. 745-750, 1999.

[29] H. B. El-Serag, "Hepatocellular carcinoma: recent trends in the United States," Gastroenterology, vol. 127, no. 5, pp. S27-S34, 2004.

[30] A. O. Kaseb, A. Hanbali, M. Cotant, M. M. Hassan, I. Wollner, and P. A. Philip, "Vascular endothelial growth factor in the management of hepatocellular carcinoma: a review of literature," Cancer: Interdisciplinary International Journal of the American Cancer Society, vol. 115, no. 21, pp. 4895-4906, 2009.

[31] R. Roskoski Jr., "Vascular endothelial growth factor (VEGF) signaling in tumor progression," Critical Reviews in Oncology/Hematology, vol. 62, no. 3, pp. 179-213, 2007.

[32] R. van der Meel, M. H. Symons, R. Kudernatsch et al., "The VEGF/Rho GTPase signalling pathway: a promising target for anti-angiogenic/anti-invasion therapy," Drug Discovery Today, vol. 16, no. 5-6, pp. 219-228, 2011.

[33] R. Yamaguchi, H. Yano, A. Iemura, S. Ogasawara, M. Haramaki, and M. Kojiro, "Expression of vascular endothelial growth factor in human hepatocellular carcinoma," Hepatology, vol. 28, no. 1, pp. 68-77, 1998.

[34] J. Zhou, Z. Y. Tang, J. Fan et al., "Expression of plateletderived endothelial cell growth factor and vascular endothelial growth factor in hepatocellular carcinoma and portal vein tumor thrombus," Journal of Cancer Research and Clinical Oncology, vol. 126, no. 1, pp. 57-61, 2000.

[35] S. Whittaker, R. Marais, and A. X. Zhu, "The role of signaling pathways in the development and treatment of hepatocellular carcinoma," Oncogene, vol. 29, no. 36, pp. 4989-5005, 2010.
[36] M. B. Thomas, R. Chadha, K. Glover et al., "Phase 2 study of erlotinib in patients with unresectable hepatocellular carcinoma," Cancer, vol. 110, no. 5, pp. 1059-1067, 2007.

[37] M. J. Hawkins, "Clinical trials of antiangiogenic agents," Current Opinion in Oncology, vol. 7, no. 1, pp. 90-93, 1995.

[38] Y. C. Shen, C. Hsu, and A. L. Cheng, "Molecular targeted therapy for advanced hepatocellular carcinoma: current status and future perspectives," Journal of Gastroenterology, vol. 45, no. 8, pp. 794-807, 2010.

[39] S. M. Wilhelm, C. Carter, L. Y. Tang et al., "BAY 43-9006 exhibits broad spectrum oral antitumor activity and targets the RAF/MEK/ERK pathway and receptor tyrosine kinases involved in tumor progression and angiogenesis," Cancer Research, vol. 64, no. 19, pp. 7099-7109, 2004.

[40] E. K. Kim and E. J. Choi, "Pathological roles of MAPK signaling pathways in human diseases," Biochimica et Biophysica Acta (BBA)-Molecular Basis of Disease, vol. 1802, no. 4, pp. 396-405, 2010.

[41] J. A. Gollob, S. Wilhelm, C. Carter, and S. L. Kelley, "Role of Raf kinase in cancer: therapeutic potential of targeting the Raf/MEK/ERK signal transduction pathway," Seminars in Oncology, vol. 33, no. 4, pp. 392-406, 2006.

[42] W. X. Schulze, L. Deng, and M. Mann, "Phosphotyrosine interactome of the ErbB-receptor kinase family," Molecular Systems Biology, vol. 1, no. 1, p. 2005, 2005.

[43] N. Zarich, J. L. Oliva, N. Martínez et al., "Grb2 is a negative modulator of the intrinsic Ras-GEF activity of hSos1," Molecular Biology of the Cell, vol. 17, no. 8, pp. 3591-3597, 2006.

[44] J. Avruch, A. Khokhlatchev, J. M. Kyriakis et al., "Ras activation of the Raf kinase: tyrosine kinase recruitment of the MAP kinase cascade," Recent Progress in Hormone Research, vol. 56, pp. 127-155, 2001.

[45] C. Huang, K. Jacobson, and M. D. Schaller, "MAP kinases and cell migration," Journal of Cell Science, vol. 117, no. 20, pp. 4619-4628, 2004.

[46] K. Balmanno and S. J. Cook, "Tumour cell survival signalling by the ERK1/2 pathway," Cell Death \& Differentiation, vol. 16, no. 3, pp. 368-377, 2009.

[47] K. J. Schmitz, J. Wohlschlaeger, H. Lang et al., "Activation of the ERK and AKT signalling pathway predicts poor prognosis in hepatocellular carcinoma and ERK activation in cancer tissue is associated with hepatitis C virus infection," Journal of Hepatology, vol. 48, no. 1, pp. 83-90, 2008.

[48] D. F. Calvisi, F. Pinna, F. Meloni et al., "Dual-specificity phosphatase 1 ubiquitination in extracellular signal-regulated kinase-mediated control of growth in human hepatocellular carcinoma," Cancer Research, vol. 68, no. 11, pp. 41924200, 2008.

[49] Y. Keshet and R. Seger, "The MAP kinase signaling cascades: a system of hundreds of components regulates a diverse array of physiological functions," in MAP Kinase Signaling Protocols, Springer, 2010.

[50] Q. Chang, Y. Zhang, K. J. Beezhold et al., "Sustained JNK1 activation is associated with altered histone $\mathrm{H} 3$ methylations in human liver cancer," Journal of Hepatology, vol. 50, no. 2, pp. 323-333, 2009.

[51] M. Das, D. S. Garlick, D. L. Greiner, and R. J. Davis, "The role of JNK in the development of hepatocellular carcinoma," Genes \& Development, vol. 25, no. 6, pp. 634-645, 2011.

[52] L. Hui, L. Bakiri, A. Mairhorfer et al., "p38 $\alpha$ suppresses normal and cancer cell proliferation by antagonizing the JNK- 
c-Jun pathway," Nature Genetics, vol. 39, no. 6, pp. 741-749, 2007.

[53] M. Soares-Silva, F. F. Diniz, G. N. Gomes, and D. Bahia, “The mitogen-activated protein kinase (MAPK) pathway: role in immune evasion by trypanosomatids," Frontiers in Microbiology, vol. 7, p. 183, 2016.

[54] P. W. Finch, X. He, M. J. Kelley et al., "Purification and molecular cloning of a secreted, Frizzled-related antagonist of Wnt action," Proceedings of the National Academy of Sciences, vol. 94, no. 13, pp. 6770-6775, 1997.

[55] P. Fedi, A. Bafico, A. N. Soria et al., "Isolation and biochemical characterization of the human Dkk-1 homologue, a novel inhibitor of mammalian Wnt signaling," Journal of Biological Chemistry, vol. 274, no. 27, pp. 19465-19472, 1999.

[56] H. Clevers, "Wnt/ $\beta$-catenin signaling in development and disease," Cell, vol. 127, no. 3, pp. 469-480, 2006.

[57] M. Shtutman, J. Zhurinsky, I. Simcha et al., "The cyclin D1 gene is a target of the $\beta$-catenin/LEF-1 pathway," Proceedings of the National Academy of Sciences, vol. 96, no. 10, pp. 55225527, 1999.

[58] W. J. Nelson and R. Nusse, "Convergence of Wnt, ß-catenin, and cadherin pathways," Science, vol. 303, no. 5663, pp. 1483-1487, 2004.

[59] J. Behari, “The Wnt/ $\beta$-catenin signaling pathway in liver biology and disease," Expert Review of Gastroenterology \& Hepatology, vol. 4, no. 6, pp. 745-756, 2010.

[60] B. Vanhaesebroeck and M. D. Waterfield, "Signaling by distinct classes of phosphoinositide 3-kinases," Experimental Cell Research, vol. 253, no. 1, pp. 239-254, 1999.

[61] A. Villanueva, D. Y. Chiang, P. Newell et al., "Pivotal role of mTOR signaling in hepatocellular carcinoma," Gastroenterology, vol. 135, no. 6, pp. 1972-1983, 2008.

[62] J. Paez and W. R. Sellers, "PI3K/PTEN/Akt pathway," in Signal Transduction in Cancer, Springer, 2004.

[63] S. Wullschleger, R. Loewith, and M. N. Hall, "TOR signaling in growth and metabolism," Cell, vol. 124, no. 3, pp. 471-484, 2006.

[64] A. Beenken and M. Mohammadi, "The FGF family: biology, pathophysiology and therapy," Nature Reviews Drug Discovery, vol. 8, no. 3, pp. 235-253, 2009.

[65] N. Turner and R. Grose, "Fibroblast growth factor signalling: from development to cancer," Nature Reviews Cancer, vol. 10, no. 2, pp. 116-129, 2010.

[66] D. M. Ornitz, J. Xu, J. S. Colvin et al., "Receptor specificity of the fibroblast growth factor family," Journal of Biological Chemistry, vol. 271, no. 25, pp. 15292-15297, 1996.

[67] V. P. Eswarakumar, I. Lax, and J. Schlessinger, "Cellular signaling by fibroblast growth factor receptors," Cytokine \& Growth Factor Reviews, vol. 16, no. 2, pp. 139-149, 2005.

[68] N. Zheng, W. Wei, and Z. Wang, "Emerging roles of FGF signaling in hepatocellular carcinoma," Translational Cancer Research, vol. 5, no. 1, pp. 1-6, 2016.

[69] K. M. Holmström and T. Finkel, "Cellular mechanisms and physiological consequences of redox-dependent signalling," Nature Reviews Molecular Cell Biology, vol. 15, no. 6, pp. 411-421, 2014.

[70] H. Sies, C. Berndt, and D. P. Jones, "Oxidative stress," Annual Review of Biochemistry, vol. 86, pp. 715-748, 2017.

[71] J. D. Morrow, K. E. Hill, R. F. Burk, T. M. Nammour, K. F. Badr, and L. J. Roberts, "A series of prostaglandin F2-like compounds are produced in vivo in humans by a non-cyclo- oxygenase, free radical-catalyzed mechanism," Proceedings of the National Academy of Sciences, vol. 87, no. 23, pp. 93839387, 1990.

[72] G. L. Milne, Q. Dai, and L. J. Roberts II, “The isoprostanes-25 years later," Biochimica et Biophysica Acta (BBA)-Molecular and Cell Biology of Lipids, vol. 1851, no. 4, pp. 433-445, 2015.

[73] K. Linhart, H. Bartsch, and H. K. Seitz, "The role of reactive oxygen species (ROS) and cytochrome P-450 2E1 in the generation of carcinogenic etheno-DNA adducts," Redox Biology, vol. 3, pp. 56-62, 2014.

[74] R. S. Balaban, S. Nemoto, and T. Finkel, "Mitochondria, oxidants, and aging," Cell, vol. 120, no. 4, pp. 483-495, 2005.

[75] F. J. Gonzalez, "Role of cytochromes P450 in chemical toxicity and oxidative stress: studies with CYP2E1," Mutation Research/Fundamental and Molecular Mechanisms of Mutagenesis, vol. 569, no. 1-2, pp. 101-110, 2005.

[76] K. A. Salman and S. Ashraf, "Reactive oxygen species: a link between chronic inflammation and cancer," Asia-Pacific Journal of Molecular Biology and Biotechnology., vol. 22, pp. 42-49, 2015.

[77] F. P. Guengerich, "Common and uncommon cytochrome $\mathrm{P} 450$ reactions related to metabolism and chemical toxicity," Chemical Research in Toxicology, vol. 14, no. 6, pp. 611-650, 2001.

[78] A. R. Modi and J. H. Dawson, "Oxidizing intermediates in P450 catalysis: a case for multiple oxidants," Monooxygenase, Peroxidase and Peroxygenase Properties and Mechanisms of Cytochrome, vol. P450, pp. 63-81, 2015.

[79] A. Veith and B. Moorthy, "Role of cytochrome P450s in the generation and metabolism of reactive oxygen species," Current Opinion in Toxicology, vol. 7, pp. 44-51, 2018.

[80] D. Pessayre, A. Berson, B. Fromenty, and A. Mansouri, "Mitochondria in steatohepatitis," Seminars in Liver Disease, vol. 21, no. 1, pp. 57-70, 2001.

[81] M. Vacca, M. Allison, J. L. Griffin, and A. Vidal-Puig, "Fatty acid and glucose sensors in hepatic lipid metabolism: implications in NAFLD," Seminars in Liver Disease, vol. 35, no. 3, pp. 250-261, 2015.

[82] A. M. Gusdon, K. X. Song, and S. Qu, "Nonalcoholic fatty liver disease: pathogenesis and therapeutics from a mitochondria-centric perspective," Oxidative Medicine and Cellular Longevity, vol. 2014, Article ID 637027, 20 pages, 2014.

[83] G. Tell, C. Vascotto, and C. Tiribelli, “Alterations in the redox state and liver damage: hints from the EASL Basic School of Hepatology," Journal of Hepatology, vol. 58, no. 2, pp. 365374, 2013.

[84] T. Finkel, "Signal transduction by mitochondrial oxidants," Journal of Biological Chemistry, vol. 287, no. 7, pp. 44344440, 2012.

[85] R. Scherz-Shouval, E. Shvets, E. Fass, H. Shorer, L. Gil, and Z. Elazar, "Reactive oxygen species are essential for autophagy and specifically regulate the activity of Atg4," The EMBO Journal, vol. 26, no. 7, pp. 1749-1760, 2007.

[86] K. Begriche, A. Igoudjil, D. Pessayre, and B. Fromenty, "Mitochondrial dysfunction in NASH: causes, consequences and possible means to prevent it," Mitochondrion, vol. 6, no. 1, pp. 1-28, 2006.

[87] K. Begriche, J. Massart, and B. Fromenty, "Effects of $\beta$-aminoisobutyric acid on leptin production and lipid homeostasis: mechanisms and possible relevance for the prevention of 
obesity," Fundamental \& Clinical Pharmacology, vol. 24, no. 3, pp. 269-282, 2010.

[88] H. Z. Lin, S. Q. Yang, C. Chuckaree, F. Kuhajda, G. Ronnet, and A. M. Diehl, "Metformin reverses fatty liver disease in obese, leptin-deficient mice," Nature Medicine, vol. 6, no. 9, pp. 998-1003, 2000.

[89] T. C. Delgado, F. L. Otsoa, and M. L. Martinez-Chantar, "Post-translational modifiers of liver kinase B1/Serine/threonine kinase II in hepatocellular carcinoma," Journal of Hepatocellular Carcinoma, vol. 6, pp. 85-91, 2019.

[90] J. Li, C. Zhang, H. Jiang, and J. Cheng, “Andrographolide inhibits hypoxia-inducible factor-1 through phosphatidylinositol 3-kinase/AKT pathway and suppresses breast cancer growth," OncoTargets and Therapy, vol. 8, pp. 427-435, 2015.

[91] H. Naz, M. Tarique, S. Ahmad et al., "Hesperidin-CAMKIV interaction and its impact on cell proliferation and apoptosis in the human hepatic carcinoma and neuroblastoma cells," Journal of Cellular Biochemistry, vol. 120, no. 9, pp. 1511915130, 2019.

[92] R. M. Carr, P. A. R. Duran, E. J. Tolosa et al., "The extracellular sulfatase SULF2 promotes liver tumorigenesis by stimulating assembly of a promoter looping GLI1-STAT3 transcriptional complex," Journal of Biological Chemistry, vol. 295, no. 9, pp. 2698-2712, 2020.

[93] R. K. Jain, D. G. Duda, J. W. Clark, and J. S. Loeffler, "Lessons from phase III clinical trials on anti-VEGF therapy for cancer," Nature Clinical Practice Oncology, vol. 3, no. 1, pp. 2440, 2006.

[94] S. Y. Lee and S. M. Chung, "Neovastat (Æ-941) inhibits the airway inflammation via VEGF and HIF- $2 \alpha$ suppression," Vascular Pharmacology, vol. 47, no. 5-6, pp. 313-318, 2007.

[95] K. T. Flaherty, J. R. Infante, A. Daud et al., "Combined BRAF and MEK inhibition in melanoma with BRAF V600 mutations," New England Journal of Medicine, vol. 367, no. 18, pp. 1694-1703, 2012.

[96] J. Wei, J. Hu, L. Wang et al., "Discovery of a first-in-class mitogen-activated protein kinase kinase 1/2 degrader," Journal of Medicinal Chemistry, vol. 62, no. 23, pp. 1089710911, 2019.

[97] A. Sebio, M. Kahn, and H. J. Lenz, "The potential of targeting Wnt $/ \beta$-catenin in colon cancer," Expert Opinion on Therapeutic Targets, vol. 18, no. 6, pp. 611-615, 2014.

[98] K. H. Emami, C. Nguyen, H. Ma et al., "A small molecule inhibitor of $\beta$-catenin/cyclic AMP response elementbinding protein transcription," Proceedings of the National Academy of Sciences, vol. 101, no. 34, pp. 12682-12687, 2004.

[99] J. Harb, P. J. Lin, and J. Hao, "Recent development of Wnt signaling pathway inhibitors for cancer therapeutics," Current Oncology Reports, vol. 21, no. 2, p. 12, 2019.

[100] S. E. Herman, A. L. Gordon, A. J. Wagner et al., "Phosphatidylinositol 3-kinase- $\delta$ inhibitor CAL-101 shows promising preclinical activity in chronic lymphocytic leukemia by antagonizing intrinsic and extrinsic cellular survival signals," Blood, vol. 116, no. 12, pp. 2078-2088, 2010.

[101] D. A. Sabbah, R. Hajjo, S. K. Bardaweel, and H. A. Zhong, "Phosphatidylinositol 3-kinase (PI3K) inhibitors: a recent update on inhibitor design and clinical trials (2016-2020)," Expert Opinion on Therapeutic Patents, vol. 31, no. 10, pp. 1-16, 2021.
[102] J. R. Brown, "Phosphatidylinositol 3 kinase $\delta$ inhibitors: present and future," Cancer Journal, vol. 25, no. 6, pp. 394-400, 2019.

[103] R. Roskoski Jr., "Properties of FDA-approved small molecule protein kinase inhibitors: a 2020 update," Pharmacological Research, vol. 152, article 104609, 2020.

[104] R. Roskoski, "Properties of FDA-approved small molecule protein kinase inhibitors: a 2021 update," Pharmacological Research, vol. 165, article 105463, 2021.

[105] B. N. Ames, "Micronutrients prevent cancer and delay aging," Toxicology Letters, vol. 102, pp. 5-18, 1998.

[106] D. A. Cox and M. L. Cohen, "Effects of oxidized low-density lipoprotein on vascular contraction and relaxation: clinical and pharmacological implications in atherosclerosis," Pharmacological Reviews, vol. 48, no. 1, pp. 3-19, 1996.

[107] T. Finkel and N. J. Holbrook, "Oxidants, oxidative stress and the biology of ageing," Nature, vol. 408, no. 6809, pp. 239$247,2000$.

[108] V. Sharma, P. Janmeda, R. Paliwal, and S. Sharma, "Antihepatotoxic activity of Euphorbia neriifolia extract against Nnitrosodiethylamine-induced hepatocarcinogenesis in mice," Zhong xi yijie he xue bao= Journal of Chinese integrative medicine, vol. 10, no. 11, pp. 1303-1309, 2012.

[109] S. Sharma, "Chemoprotective activity of hydro-ethanolic extract of Euphorbia neriifolia Linn leaves against DENAinduced liver carcinogenesis in mice," Biology and Medicine, vol. 3, pp. 36-44, 2011.

[110] S. V. Pracheta, R. Paliwal, and S. Sharma, "In vitro free radical scavenging and antioxidant potential of ethanolic extract of Euphorbia neriifolia Linn," International Journal of Pharmacy and Pharmaceutical Sciences, vol. 3, no. 1, pp. 238-242, 2011.

[111] R. Paliwal, V. Sharma, and S. S. Pracheta, "Hepatoprotective and antioxidant potential of Moringa oleifera pods against DMBA-induced hepatocarcinogenesis in male mice," International Journal of Drug Development \& Research, vol. 3, no. 2, pp. 128-138, 2011.

[112] D. D. Kitts, A. N. Wijewickreme, and C. Hu, "Antioxidant properties of a North American ginseng extract," Molecular and Cellular Biochemistry, vol. 203, no. 1, pp. 1-10, 2000.

[113] K. G. Lee and T. Shibamoto, "Antioxidant properties of aroma compounds isolated from soybeans and mung beans," Journal of Agricultural and Food Chemistry, vol. 48, no. 9, pp. 4290-4293, 2000.

[114] H. Jiao and S. Y. Wang, "Correlation of antioxidant capacities to oxygen radical scavenging enzyme activities in blackberry," Journal of Agricultural and Food Chemistry, vol. 48, no. 11, pp. 5672-5676, 2000.

[115] S. V. Pracheta, R. Paliwal, and S. Sharma, "Preliminary phytochemical screening and in vitro antioxidant potential of hydro-ethanolic extract of Euphorbia neriifolia Linn," International Journal of PharmTech Research, vol. 3, no. 1, pp. 124-132, 2011.

[116] A. Prakash, D. Jain, and R. Tripathi, "Pharmacognostical analysis of different parts of Cyperus rotundus L.," Plant Science Today, vol. 6, no. sp1, pp. 607-612, 2019.

[117] D. Jain, P. Chaudhary, A. Kotnala, R. Hossain, K. Bisht, and M. N. Hossain, "Hepatoprotective activity of medicinal plants: a mini review," Journal of Medicinal Plants, vol. 8, no. 5, pp. 183-188, 2020.

[118] D. Jain, N. Uniyal, D. Mitra, and P. Janmeda, “Traditional resources and use of aromatic and ethnomedicinal plants in 
Uttarakhand: compliment of nature," International Journal of Herbal Medicine, vol. 8, no. 5, pp. 88-95, 2020.

[119] K. S. B. Razzak, D. Jain, M. N. Hossain, and A. Bushra, "Plant edible vaccines: a natural way of vaccination," Vigyan Varta, vol. 1, no. 5, pp. 21-24, 2020.

[120] S. P. Hussain, L. J. Hofseth, and C. C. Harris, "Radical causes of cancer," Nature Reviews Cancer, vol. 3, no. 4, pp. 276-285, 2003.

[121] R. Olinski, A. Siomek, R. Rozalski et al., "Oxidative damage to DNA and antioxidant status in aging and age-related diseases," Acta Biochimica Polonica, vol. 54, no. 1, pp. 11-26, 2007.

[122] P. Abraham, V. K. Kolli, and S. Rabi, "Melatonin attenuates methotrexate-induced oxidative stress and renal damage in rats," Cell Biochemistry and Function, vol. 28, no. 5, pp. 426-433, 2010.

[123] S. Rashid, N. Ali, S. Nafees, S. K. Hasan, and S. Sultana, "Mitigation of 5-fluorouracil induced renal toxicity by chrysin via targeting oxidative stress and apoptosis in Wistar rats," Food and Chemical Toxicology, vol. 66, pp. 185-193, 2014.

[124] D. N. Tripathi and G. B. Jena, "Intervention of astaxanthin against cyclophosphamide-induced oxidative stress and DNA damage: a study in mice," Chemico-Biological Interactions, vol. 180, no. 3, pp. 398-406, 2009.

[125] S. Nafees, S. Rashid, N. Ali, S. K. Hasan, and S. Sultana, "Rutin ameliorates cyclophosphamide induced oxidative stress and inflammation in Wistar rats: role of $\mathrm{NF} \kappa \mathrm{B} / \mathrm{MAPK}$ pathway," Chemicobiological Interactions, vol. 231, pp. 98$107,2015$.

[126] S. Li, H. Y. Tan, N. Wang et al., "The role of oxidative stress and antioxidants in liver diseases," International Journal of Molecular Sciences, vol. 16, no. 11, pp. 26087-26124, 2015.

[127] V. Sharma, S. Sharma, and S. S. Pracheta, "Lead induced hepatotoxicity in male Swiss albino mice: the protective potential of the hydromethanolic extract of Withania somnifera," International Journal of Pharmaceutical Sciences and Research, vol. 7, pp. 116-121, 2011.

[128] B. Mayer and B. Hemmens, "Biosynthesis and action of nitric oxide in mammalian cells," Trends in Biochemical Sciences, vol. 22, no. 12, pp. 477-481, 1997.

[129] D. Jain, P. Chaudhary, N. Varshney, and P. Janmeda, "Carcinogenic effects of $\mathrm{N}$-nitroso compounds in the environment," Environment Conservation Journal, vol. 21, no. 3, pp. 25-41, 2020.

[130] F. A. Yassen, A. T. Keshta, and N. A. Ghonaim, “Andrographolide and resveratrol effect against hepatocellular carcinoma induced in male albino rats," Biochemistry Letters, vol. 11, no. 1, pp. 89-101, 2015.

[131] X. Zou, J. Liang, J. Sun et al., “Allicin sensitizes hepatocellular cancer cells to anti-tumor activity of 5-fluorouracil through ROS-mediated mitochondrial pathway," Journal of Pharmacological Sciences, vol. 131, no. 4, pp. 233-240, 2016.

[132] X. Dong, J. Fu, X. Yin et al., "Induction of apoptosis in HepaRG cell line by aloe-emodin through generation of reactive oxygen species and the mitochondrial pathway," Cellular Physiology and Biochemistry, vol. 42, no. 2, pp. 685-696, 2017.

[133] S. Nadi, M. Elahi, S. Moradi, and A. Banaei, "Radioprotective effect of arbutin in megavoltage therapeutic X-irradiated mice using liver enzymes assessment," Journal of Biomedical Physics \& Engineering, vol. 9, no. 5, p. 533, 2019.
[134] P. Zhang, Q. Wang, Z. Lin, P. Yang, K. Dou, and R. Zhang, "Berberine inhibits growth of liver cancer cells by suppressing glutamine uptake," OncoTargets and Therapy, vol. 12, p. 11751, 2019.

[135] N. Subramaniam, P. Kannan, and D. Thiruvengadam, "Hepatoprotective effect of boldine against diethylnitrosamine-induced hepatocarcinogenesis in Wistar rats," Journal of Biochemical and Molecular Toxicology, vol. 33, no. 12, article e22404, 2019.

[136] W. Wang, Y. Wang, M. Liu et al., "Betulinic acid induces apoptosis and suppresses metastasis in hepatocellular carcinoma cell lines in vitro and in vivo," Journal of Cellular and Molecular Medicine, vol. 23, no. 1, pp. 586-595, 2019.

[137] K. C. Brown, T. R. Witte, W. E. Hardman et al., "Capsaicin displays anti-proliferative activity against human small cell lung cancer in cell culture and nude mice models via the E2F pathway," PLoS One, vol. 5, no. 4, article e10243, 2010.

[138] J. I. Okano, T. Nagahara, K. Matsumoto, and Y. Murawaki, "Caffeine inhibits the proliferation of liver cancer cells and activates the MEK/ERK/EGFR signalling pathway," Basic \& Clinical Pharmacology \& Toxicology, vol. 102, no. 6, pp. 543-551, 2008.

[139] A. Amin, A. Hamza, S. Daoud et al., "Saffron-based crocin prevents early lesions of liver cancer: in vivo, in vitro and network analyses," Recent Patents on Anti-Cancer Drug Discovery, vol. 11, no. 1, pp. 121-133, 2016.

[140] A. Sabt, O. M. Abdelhafez, R. S. El-Haggar et al., "Novel coumarin-6-sulfonamides as apoptotic anti-proliferative agents: synthesis, in vitro biological evaluation, and QSAR studies," Journal of Enzyme Inhibition and Medicinal Chemistry, vol. 33, no. 1, pp. 1095-1107, 2018.

[141] K. I. Lin, C. C. Lin, S. M. Kuo et al., "Carnosic acid impedes cell growth and enhances anticancer effects of carmustine and lomustine in melanoma," Bioscience Reports, vol. 38, no. 4, 2018.

[142] J. Wang, C. Wang, and G. Bu, "Curcumin inhibits the growth of liver cancer stem cells through the phosphatidylinositol 3kinase/protein kinase $\mathrm{B} /$ mammalian target of rapamycin signaling pathway," Experimental and Therapeutic Medicine, vol. 15, no. 4, pp. 3650-3658, 2018.

[143] H. J. Park, Y. K. Jeon, D. H. You, and M. J. Nam, "Daidzein causes cytochrome c-mediated apoptosis via the Bcl-2 family in human hepatic cancer cells," Food and Chemical Toxicology, vol. 60, pp. 542-549, 2013.

[144] R. Poojari, S. Gupta, G. Maru, B. Khade, and S. Bhagwat, "Chemopreventive and hepatoprotective effects of embelin on $\mathrm{N}$-nitrosodiethylamine and carbon tetrachloride induced preneoplasia and toxicity in rat liver," Asian Pacific Journal of Cancer Prevention, vol. 11, no. 4, pp. 1015-1020, 2010.

[145] J. Wang, M. L. Lu, H. L. Dai, S. P. Zhang, H. X. Wang, and N. Wei, "Esculetin, a coumarin derivative, exerts in vitro and in vivo antiproliferative activity against hepatocellular carcinoma by initiating a mitochondrial-dependent apoptosis pathway," Brazilian Journal of Medical and Biological Research, vol. 48, no. 3, pp. 245-253, 2015.

[146] Y. S. Kim, Y. M. Lee, T. I. Oh et al., "Emodin sensitizes hepatocellular carcinoma cells to the anti-cancer effect of sorafenib through suppression of cholesterol metabolism," International Journal of Molecular Sciences, vol. 19, no. 10, p. $3127,2018$.

[147] H. Khan, W. Jia, Z. Yu et al., "Emodin succinyl ester inhibits malignant proliferation and migration of hepatocellular 
carcinoma by suppressing the interaction of AR and EZH2," Biomedicine \& Pharmacotherapy, vol. 128, article 110244, 2020.

[148] J. Chen, L. Chen, T. Lu et al., "ER $\alpha 36$ is an effective target of epigallocatechin-3-gallate in hepatocellular carcinoma," International Journal of Clinical and Experimental Pathology, vol. 12, no. 9, p. 3222, 2019.

[149] M. Sanaei, F. Kavoosi, A. Valiani, and M. A. Ghobadifar, "Effect of genistein on apoptosis and proliferation of hepatocellular carcinoma Hepa1-6 cell line," International Journal of Preventive Medicine, vol. 9, 2018.

[150] S. Jagan, G. Ramakrishnan, P. Anandakumar, S. Kamaraj, and T. Devaki, "Antiproliferative potential of gallic acid against diethylnitrosamine-induced rat hepatocellular carcinoma," Molecular and Cellular Biochemistry, vol. 319, no. 1, pp. 51-59, 2008.

[151] P. Kuang, W. Zhao, W. Su et al., " $18 \beta$-glycyrrhetinic acid inhibits hepatocellular carcinoma development by reversing hepatic stellate cell-mediated immunosuppression in mice," International Journal of Cancer, vol. 132, no. 8, pp. 18311841, 2013.

[152] S. Yumnam, H. S. Park, M. K. Kim et al., "Hesperidin induces paraptosis like cell death in hepatoblatoma, HepG2 cells: involvement of ERK1/2 MAPK," PloS One, vol. 9, no. 6, article e101321, 2014.

[153] W. Songjang and A. Jiraviriyakul, "Honokiol and magnolol inhibit growth, metastasis and induce apoptosis in human cholangiocarcinoma," Biomedical and Pharmacology Journal, vol. 12, no. 2, pp. 759-773, 2019.

[154] G. Zhu, X. Liu, H. Li, Y. Yan, X. Hong, and Z. Lin, "Kaempferol inhibits proliferation, migration, and invasion of liver cancer HepG2 cells by down-regulation of microRNA-21," International Journal of Immunopathology and Pharmacology, vol. 32, 2018.

[155] T. K. W. Lee, A. Castilho, V. C. H. Cheung, K. H. Tang, S. Ma, and I. O. L. Ng, "Lupeol targets liver tumor-initiating cells through phosphatase and tensin homolog modulation," Hepatology, vol. 53, no. 1, pp. 160-170, 2011.

[156] Y. D. Wang, X. J. Sun, W. J. Yang, J. Li, and J. J. Yin, "Magnolol exerts anticancer activity in hepatocellular carcinoma cells through regulating endoplasmic reticulum stress-mediated apoptotic signaling," OncoTargets and Therapy, vol. 11, p. 5219, 2018.

[157] P. B. Pal, K. Sinha, and P. C. Sil, "Mangiferin, a natural xanthone, protects murine liver in $\mathrm{Pb}$ (II) induced hepatic damage and cell death via MAP kinase, NF- $\kappa$ B and mitochondria dependent pathways," PloS One, vol. 8, no. 2, article e56894, 2013.

[158] D. Arul and P. Subramanian, "Naringenin (citrus flavonone) induces growth inhibition, cell cycle arrest and apoptosis in human hepatocellular carcinoma cells," Pathology \& Oncology Research, vol. 19, no. 4, pp. 763-770, 2013.

[159] C. M. Yan, E. Q. Chai, H. Y. Cai, G. Y. Miao, and W. Ma, "Oleuropein induces apoptosis via activation of caspases and suppression of phosphatidylinositol 3-kinase/protein kinase B pathway in HepG2 human hepatoma cell line," Molecular Medicine Reports, vol. 11, no. 6, pp. 4617-4624, 2015.

[160] Y. Y. Zhu, H. Y. Huang, and Y. L. Wu, "Anticancer and apoptotic activities of oleanolic acid are mediated through cell cycle arrest and disruption of mitochondrial membrane potential in HepG2 human hepatocellular carcinoma cells," Molecular Medicine Reports, vol. 12, no. 4, pp. 5012-5018, 2015.
[161] J. Sun, C. Zhang, Y. L. Bao et al., "Parthenolide-induced apoptosis, autophagy and suppression of proliferation in HepG2 cells," Asian Pacific Journal of Cancer Prevention, vol. 15, no. 12, pp. 4897-4902, 2014.

[162] S. Hao, Y. Yan, S. Li et al., "The in vitro anti-tumor activity of phycocyanin against non-small cell lung cancer cells," Marine Drugs, vol. 16, no. 6, p. 178, 2018.

[163] L. Wu, J. Li, T. Liu et al., "Quercetin shows anti-tumor effect in hepatocellular carcinoma LM3 cells by abrogating JAK2/STAT3 signaling pathway," Cancer Medicine, vol. 8, no. 10, pp. 4806-4820, 2019.

[164] M. Alía, R. Mateos, S. Ramos, E. Lecumberri, L. Bravo, and L. Goya, "Influence of quercetin and rutin on growth and antioxidant defense system of a human hepatoma cell line (HepG2)," European Journal of Nutrition, vol. 45, no. 1, pp. 19-28, 2006.

[165] W. Cao, C. Hu, L. Wu, L. Xu, and W. Jiang, "Rosmarinic acid inhibits inflammation and angiogenesis of hepatocellular carcinoma by suppression of NF- $\kappa \mathrm{B}$ signaling in $\mathrm{H} 22$ tumorbearing mice," Journal of pharmacological sciences, vol. 132, no. 2, pp. 131-137, 2016.

[166] P. Parekh, L. Motiwale, N. Naik, and K. V. K. Rao, "Downregulation of cyclin D1 is associated with decreased levels of p38 MAP kinases, Akt/PKB and Pak1 during chemopreventive effects of resveratrol in liver cancer cells," Experimental and Toxicologic Pathology, vol. 63, no. 1-2, pp. 167-173, 2011.

[167] X. Hu, S. Lin, D. Yu, S. Qiu, X. Zhang, and R. Mei, “A preliminary study: the anti-proliferation effect of salidroside on different human cancer cell lines," Cell biology and Toxicology, vol. 26, no. 6, pp. 499-507, 2010.

[168] H. S. Son, H. Y. Kwon, E. J. Sohn et al., "Activation of AMPactivated protein kinase and phosphorylation of glycogen synthase kinase $3 \beta$ mediate ursolic acid induced apoptosis in HepG2 liver cancer cells," Phytotherapy Research, vol. 27, no. 11, pp. 1714-1722, 2013.

[169] Y. X. Wang, W. B. Ding, and C. W. Dong, "Withaferin A suppresses liver tumor growth in a nude mouse model by downregulation of cell signaling pathway leading to invasion and angiogenesis," Tropical Journal of Pharmaceutical Research, vol. 14, no. 6, pp. 1005-1011, 2015.

[170] T. L. Shi, L. Zhang, Q. Y. Cheng et al., "Xanthatin induces apoptosis by activating endoplasmic reticulum stress in hepatoma cells," European Journal of Pharmacology, vol. 843, pp. 1-11, 2019.

[171] P. Arulselvan, M. T. Fard, W. S. Tan et al., "Role of antioxidants and natural products in inflammation," Oxidative medicine and cellular longevity, vol. 2016, Article ID 5276130, 15 pages, 2016.

[172] I. Sakaida, M. Tsuchiya, K. Kawaguchi, T. Kimura, S. Terai, and K. Okita, "HerbalmedicineInchin-ko-to (TJ-135) prevents liver fibrosis and enzyme-altered lesions in rat liver cirrhosis induced by a choline-deficient L-amino acid-defined diet," Journal of Hepatology, vol. 38, no. 6, pp. 762-769, 2003.

[173] H. J. Lin, J. Y. Chen, C. F. Lin et al., "Hepatoprotective effects of Yi Guan Jian, an herbal medicine, in rats with dimethylnitrosamine-induced liver fibrosis," Journal of Ethnopharmacology, vol. 134, no. 3, pp. 953-960, 2011.

[174] X. Lin, S. Zhang, Q. Huang et al., "Protective effect of FufangLiu-Yue-Qing, a traditional Chinese herbal formula, on $\mathrm{CCl}_{4}$ induced liver fibrosis in rats," Journal of Ethnopharmacology, vol. 142, no. 2, pp. 548-556, 2012. 
[175] J. Lv, Z. Zhao, Y. Chen et al., "The Chinese herbal decoction danggui buxue tang inhibits angiogenesis in a rat model of liver fibrosis," Evidence-Based Complementary and Alternative Medicine, vol. 2012, Article ID 284963, 11 pages, 2012.

[176] F. Lin, K. L. Marcelo, K. Rajapakshe et al., "The CaMKK2/CaMKIV is an essential regulator of hepatic cancer," Hepatology, vol. 62, no. 2, pp. 505-520, 2015.

[177] H. Gao and J. Wang, "Andrographolide inhibits multiple myeloma cells by inhibiting the TLR4/NF-kappa B signaling pathway," Molecular Medicine Reports, vol. 13, pp. 18271832, 2016.

[178] E. J. Gunn, J. T. Williams, D. T. Huynh et al., "The natural products parthenolide and andrographolide exhibit anticancer stem cell activity in multiple myeloma," Leukemia \& Lymphoma, vol. 52, pp. 1085-1097, 2011.

[179] Y. Zhang, X. Li, D. Zou et al., "Treatment of type 2 diabetes and dyslipidemia with the natural plant alkaloid berberine," The Journal of Clinical Endocrinology \& Metabolism, vol. 93, no. 7, pp. 2559-2565, 2008.

[180] J. J. Jang, K. J. Cho, Y. S. Lee, and J. H. Bae, "Different modifying responses of capsaicin in a widespectrum initiation model of F344 rat," Journal of Korean Medical Science, vol. 6, pp. 31-36, 1991.

[181] J. A. Kim, Y. S. Kang, and Y. S. Lee, "A phospholipase Cdependent intracellular $\mathrm{Ca} 2+$ release pathway mediates the capsaicin-induced apoptosis in HepG2 human hepatoma cells," Archives of Pharmacal Research, vol. 28, pp. 73-80, 2005.

[182] G. Galati and P. J. O’Brien, "Cytoprotective and anticancer properties of coenzyme Q vs. capsaicin," Biofactors, vol. 18, pp. 195-205, 2003.

[183] R. A. Sharma, S. A. Euden, S. L. Platton et al., "Phase I clinical trial of oral curcumin: biomarkers of systemic activity and compliance," Clinical Cancer Research, vol. 10, no. 20, pp. 6847-6854, 2004.

[184] M. Kanai, Y. Otsuka, K. Otsuka et al., “A phase I study investigating the safety and pharmacokinetics of highly bioavailable curcumin (Theracurmin) in cancer patients," Cancer Chemotherapy and Pharmacology, vol. 71, no. 6, pp. 1521-1530, 2013.

[185] M. Bayet-Robert, F. Kwiatkowski, M. Leheurteur et al., "Phase I dose escalation trial of docetaxel plus curcumin in patients with advanced and metastatic breast cancer," Cancer Biology \& Therapy, vol. 9, no. 1, pp. 8-14, 2010.

[186] H. Mahammedi, E. Planchat, M. Pouget et al., "The new combination docetaxel, prednisone and curcumin in patients with castration-resistant prostate cancer: a pilot phase II study," Oncology, vol. 90, no. 2, pp. 69-78, 2016.

[187] R. Epelbaum, M. Schaffer, B. Vizel, V. Badmaev, and G. BarSela, "Curcumin and gemcitabine in patients with advanced pancreatic cancer," Nutrition and Cancer, vol. 62, no. 8, pp. 1137-1141, 2010.

[188] Y. Zhang, Q. Li, D. Zhou, and H. Chen, "Genistein, a soya isoflavone, prevents azoxymethane-induced up-regulation of WNT/beta-catenin signalling and reduces colon preneoplasia in rats," British Journal of Nutrition, vol. 109, no. 1, pp. 33-42, 2013.

[189] Y. Wang, Z. Wei, and X. Wang, "Enhancement of anti-tumor activity of ursolic acid by nanostructured lipid carriers," Nanomedicine: Nanotechnology, Biology and Medicine, vol. 14, pp. 1743-1885, 2018.

[190] S. Suman, T. P. Das, S. Sirimulla, H. Alatassi, M. K. Ankem, and C. Damodaran, "Withaferin-A suppress AKT induced tumor growth in colorectal cancer cells," Oncotarget, vol. 7, no. 12, pp. 13854-13864, 2016.

[191] D. Mansuy, "Metabolism of xenobiotics: beneficial and adverse effects," Biologieaujourd'hui, vol. 207, no. 1, pp. 3337, 2013.

[192] P. Jancova, P. Anzenbacher, and E. Anzenbacherova, "Phase II drug metabolizing enzymes," Biomedical Papers, vol. 154, no. 2, pp. 103-116, 2010.

[193] V. Kaur, M. Kumar, A. Kumar, K. Kaur, V. S. Dhillon, and S. Kaur, "Pharmacotherapeutic potential of phytochemicals: implications in cancer chemoprevention and future perspectives," Biomedicine \& Pharmacotherapy, vol. 97, pp. 564-586, 2018.

[194] A. Azqueta and A. Collins, "Polyphenols and DNA damage: a mixed blessing," Nutrients, vol. 8, no. 12, p. 785, 2016.

[195] M. R. Kelly, J. Xu, K. E. Alexander, and G. Loo, "Disparate effects of similar phenolic phytochemicals as inhibitors of oxidative damage to cellular DNA," Mutation Research/DNA Repair, vol. 485, no. 4, pp. 309-318, 2001.

[196] P. Rajendran, E. Ho, D. E. Williams, and R. H. Dashwood, "Dietary phytochemicals, HDAC inhibition, and DNA damage/repair defects in cancer cells," Clinical Epigenetics, vol. 3, no. 1, pp. 1-23, 2011.

[197] S. Reuter, S. C. Gupta, M. M. Chaturvedi, and B. B. Aggarwal, "Oxidative stress, inflammation, and cancer: how are they linked?," Free Radical Biology and Medicine, vol. 49, no. 11, pp. 1603-1616, 2010.

[198] G. Waris and H. Ahsan, "Reactive oxygen species: role in the development of cancer and various chronic conditions," Journal of Carcinogenesis, vol. 5, p. 14, 2006.

[199] R. J. DeBerardinis, "Is cancer a disease of abnormal cellular metabolism? New angles on an old idea," Genetics in Medicine, vol. 10, no. 11, pp. 767-777, 2008.

[200] W. Zhang, Y. Liu, X. Chen, and S. C. Bergmeier, "Novel inhibitors of basal glucose transport as potential anticancer agents," Bioorganic \& Medicinal Chemistry Letters, vol. 20, no. 7, pp. 2191-2194, 2010.

[201] M. Bayet-Robert and D. Morvan, "Metabolomics reveals metabolic targets and biphasic responses in breast cancer cells treated by curcumin alone and in association with docetaxel," PloS One, vol. 8, no. 3, article e57971, 2013.

[202] H. Zaid, M. Silbermann, A. Amash, D. Gincel, E. Abdel-Sattar, and N. B. Sarikahya, "Medicinal plants and natural active compounds for cancer chemoprevention/chemotherapy," Evidence-Based Complementary and Alternative Medicine, vol. 2017, Article ID 7952417, 2 pages, 2017.

[203] B. Hazra, S. Ghosh, A. Kumar, and B. N. Pandey, "The prospective role of plant products in radiotherapy of cancer: a current overview," Frontiers in Pharmacology, vol. 2, no. 94, pp. 1-13, 2012.

[204] V. Kuruba and P. Gollapalli, "Natural radioprotectors and their impact on cancer drug discovery," Radiation Oncology Journal, vol. 36, no. 4, pp. 265-275, 2018.

[205] C. P. Wu, S. Ohnuma, and S. V. Ambudkar, "Discovering natural product modulators to overcome multidrug resistance in cancer chemotherapy," Current Pharmaceutical Biotechnology, vol. 12, no. 4, pp. 609-620, 2011.

[206] K. Sak, "Chemotherapy and dietary phytochemical agents," Chemotherapy Research and Practice, vol. 2012, Article ID 282570, 11 pages, 2012. 